\title{
Zero-tillage as a pathway for sustainable wheat intensification in the Eastern Indo-Gangetic Plains: does it work in farmers' fields?
}

\author{
Alwin Keil ${ }^{1}$ - Alwin D'souza ${ }^{1}$ • Andrew McDonald ${ }^{2}$
}

Received: 6 March 2015 / Accepted: 3 August 2015 /Published online: 28 August 2015

(C) The Author(s) 2015. This article is published with open access at Springerlink.com

\begin{abstract}
In controlled-condition field trials across South Asia, zero-tillage (ZT) has demonstrated considerable scope for enhancing wheat productivity in the Indo-Gangetic Plains (IGP) while using less energy and irrigation water. However, studies that quantify the impact of ZT in farmers' fields are scarce, especially in the less productive and densely populated Eastern IGP, an area that the Indian government is targeting for investment to address current and future food insecurity. Furthermore, a recent global meta-analysis has questioned the yield benefits of ZT, especially when permanent soil cover with crop residues is not maintained. To assess the realworld performance of ZT wheat in Eastern India, we quantified the productivity impact of current ZT practices in the State of Bihar, based on a random sample of 1000 wheatgrowing households, stratified by ZT adoption status. CobbDouglas stochastic production frontiers estimated the effect of ZT on wheat output while controlling for potential selection bias between ZT users and non-users regarding crop management. In contrast to the global meta-analysis, we found that the prevailing ZT practices without full residue retention led to a robust yield gain over conventional-tillage wheat across different agro-ecological zones, amounting to $498 \mathrm{~kg} \mathrm{ha}^{-1}$ (19\%), on average. The economic benefit from ZT related yield increase and cost savings in wheat production amounted
\end{abstract}

Alwin Keil

a.keil@cgiar.org

Alwin D'souza

a.dsouza@cgiar.org

Andrew McDonald

A.McDonald@cgiar.org

1 CIMMYT-India, CG Block, National Agricultural Science Centre (NASC) Complex, DPS Marg, New Delhi 110012, India

2 CIMMYT-Nepal, Singh Durbar Plaza Marg, Kathmandu, Nepal to $6 \%$ of total annual income among sampled households. We conclude that ZT users reap substantial benefits, and that ZT technology could play a major role in making Bihar selfsufficient in wheat. To increase access to the technology among smallholders, an expansion of the network of ZT service providers is essential and can be supported through targeted policies and development interventions.

Keywords Zero-tillage $\cdot$ Agricultural productivity $\cdot$ Technical efficiency $\cdot$ Stochastic frontier analysis $\cdot$ Bihar

JEL codes $\mathrm{O} 13 \cdot \mathrm{Q} 55$

\section{Introduction}

Enhancing the productivity of the rice-wheat cropping systems in the Indo-Gangetic Plains (IGP) is of utmost importance for ensuring food security for more than $20 \%$ of the global population (Erenstein et al. 2008; Chauhan et al. 2012). The Eastern Indian state of Bihar is a net importer of wheat with 868,000 MT purchased against a base of production of just over 5 million MT in 2010-11 (Paulsen et al. 2012). With an average of $2.14 \mathrm{MT} \mathrm{ha}^{-1}$ over the five-year period 2008/09-2012/13 (MoA 2013), Bihar has the lowest wheat yields in the IGP. Coupled with the highest population growth rate in India (MoHA 2013) and increasing per-capita wheat consumption (Paulsen et al. 2012), the gap between consumption and production is poised to widen in this densely populated state of 104 million people (MoA 2013) without concerted efforts to enhance agricultural productivity. Furthermore, the regions that currently supply wheat to Bihar, such as the Northwestern state of Punjab where wheat yields averaged 4.59 $\mathrm{MT} \mathrm{ha}^{-1}$ over the same five-year period (MoA 2013), have comparatively little scope for further boosting yields 
(Aggarwal et al. 2004). Exacerbating this scenario, there are strong imperatives in Northwestern India to reduce water resource utilization in agriculture to arrest the dramatic declines in groundwater levels that are undermining the sustainability and environmental footprint of production (Humphreys et al. 2010). In recognition of the pervasive yield gaps that characterize the Eastern IGP along with a wealth of under-developed water resources (Aggarwal et al. 2004; DoA 2008), Indian policy makers have turned their attention to meeting both state-level and national foods needs through intensification in the East through programs such as 'Bringing the Green Revolution to Eastern India (BGREI)' (http://bgrei-rkvy.nic. in). Nevertheless, a variety of factors contribute to the current scenario of low yields in the East. Identifying technical entry points and strengthened support systems for innovation that will contribute to agricultural intensification in a manner that is environmentally sustainable, socio-economically tenable, and - just as importantly - broadly scalable among smallholders presents a formidable challenge.

In many researcher-managed field trials across South Asia, zero tillage (ZT) with and without residue retention ('conservation agriculture' implies $\mathrm{ZT}$ with residue retention) has demonstrated considerable agronomic and economic benefits, while improving the environmental footprint of agriculture by reducing energy costs and improving soil and water quality (Erenstein and Laxmi 2008; Chauhan et al. 2012; Gathala et al. 2013; Mehla et al. 2000). In ZT wheat, agronomic factors leading to productivity advantages are related to (i) timesavings in crop establishment, allowing earlier sowing and, hence, reducing risks of terminal heat stress during the grain-filling phase; (ii) better control of weeds, such as Phalaris minor; (iii) better nutrient management; and (iv) water savings (Gathala et al. 2013; Mehla et al. 2000). Based on on-farm trials in Haryana, Mehla et al. (2000) estimated a ZT induced yield gain of $15.4 \%$, which they attributed to timely sowing $(9.4 \%)$ and enhanced fertilizer- and water use efficiency, as well as weed suppression $(6.0 \%)$. Despite such regional examples that demonstrate the yield advantages of ZT in the irrigated production ecologies of South Asia, the role of ZT and conservation agriculture as foundational technologies for sustainable intensification has recently been drawn into question by a global meta-analysis of paired comparisons of crop yields in ZT and conventionally tilled production systems (Pittelkow et al. 2014). The authors conclude that ZT tends to only have yield benefits in rainfed systems and must be combined with residue retention and crop rotation for these benefits to accrue. In the dominantly irrigated wheat production systems of Bihar, retaining soil cover is currently not within the reach of most farmers due to the technical limitations of the most commonly used ZT seed drills that are unsuitable for sowing crops in fields with high levels of loose crop residues. Moreover, rice straw is an important feed source for livestock in the mixed agricultural systems that predominate in the Eastern IGP.

$\mathrm{ZT}$ wheat is the most widely adopted resource conserving technology in the rice-wheat systems to date, especially in the Northwestern Indian IGP (Derpsch et al. 2010). The prevailing ZT practice uses a zero-till drill attached to a relatively small four-wheel tractor ${ }^{1}$ to sow wheat directly into unplowed fields with a single pass (Erenstein and Laxmi 2008). The typical ZT drill opens 6-13 narrow slits using inverted-T openers to place both seed and fertilizers at a depth of 7.5$10 \mathrm{~cm}$ (Mehla et al. 2000). In contrast, conventional-tillage (CT) practices in wheat typically involve 'intensive tillage with multiple passes of the tractor to accomplish plowing, harrowing, planking, and seeding operations' (Erenstein and Laxmi 2008). Since tractor ownership in Bihar is confined to relatively large farmers only, ${ }^{2}$ the vast majority of farmers depend on tillage or ZT service providers who are typically farmers themselves and usually demand payment at the time of the service. While the farm-level impacts of ZT have been well documented in some parts of the world, such as Australia (e.g., D'Emden et al. 2008) and Brazil (Bolliger et al. 2006; Casao et al. 2012), studies that quantify the impacts of ZT practices in farmers' fields in the IGP are scarce. At the same time, ZT wheat cultivation in the IGP is unique in the sense of being usually followed by transplanted rice in puddled fields, making the ZT practice discontinuous across seasons, which reduces the potential of inferring insights from other parts of the world (Erenstein and Laxmi 2008; Derpsch et al. 2010). The few existing farm-level impact studies are confined to the Northwestern IGP (Krishna and Veettil 2014; Erenstein et al. 2008), but are lacking for the less productive and highly populated Eastern IGP where ZT is a relatively new practice (Erenstein et al. 2008).

To help validate best-bet recommendations for sustainably enhancing wheat productivity in the Eastern IGP, the objectives of this paper are (1) to quantify the productivity impact of current ZT wheat practices as compared to CT wheat practices, (2) to quantify the productivity impact of early sowing of wheat, and (3) to estimate farmers' technical efficiency (TE) in wheat production and identify efficiency determinants. The article contributes to the existing body of literature in several aspects: (1) it provides evidence on ZT productivity impacts in farmers' fields in the Eastern IGP based on a large random sample of farm households; to the best of our knowledge this is the first such assessment; (2) it uses a methodologically rigorous approach to estimate the yield effect of ZT while

\footnotetext{
${ }^{1}$ Based on a random sample of ZT service providers in Bihar, tractors average $38.4 \mathrm{HP}$, with a range from 25 to $60 \mathrm{HP}(\mathrm{N}=298)$.

${ }^{2}$ Only $8,3 \%$ of our sample households own a four-wheel tractor. Their per-capita land endowment amounts to 1.27 acres as compared to 0.54 acres among the remaining households (Mann-Whitney test significant at $P<0.001)$. The use of two-wheel tractors is very uncommon in Bihar, and non-existent in combination with ZT machinery.
} 
controlling for potential selection bias between ZT users and non-users regarding crop management; (3) it estimates the effects of ZT and early sowing of wheat separately and differentiated by agro-ecology; (4) it differentiates between the ricewheat system and other wheat-based cropping patterns; (5) it estimates TE in wheat cultivation, compares TE between CT and ZT wheat plots, and identifies efficiency determinants, which is of high policy relevance in its own right.

\section{Research area, sampling procedure, and data collection}

Agriculture is the main occupation in Bihar with almost $81 \%$ of its population engaged, whereas its contribution to State domestic product is merely $42 \%$ (DoA 2008). Paddy, wheat, pulses, maize, potato, sugarcane, oil seeds, tobacco and jute are the principal crops grown. Although Bihar is endowed with good soil, sufficient rainfall and abundant groundwater, its agricultural productivity is one of the lowest among Indian states (DoA 2008). The research area is composed of six districts where the Cereal Systems Initiative for South Asia (CSISA) has focused research and out-scaling activities for sustainable intensification technologies since 2009 (www. csisa.org). Using a cluster sampling approach, data were collected in a random sample of 1000 farm households from August to October 2013, whereby the sample was stratified by ZT adoption status. In a first step, 40 villages were randomly selected out of 87 villages with at least $10 \mathrm{ZT}$ users in the target districts, as documented by CSISA. Hereby, the number of research villages per district is proportionate to the distribution of eligible villages, resulting in three research villages each in Begusarai, Lakhisarai and Vaishali districts, six villages each in Buxar and Samastipur, and 19 villages in Bhojpur district. Since reliable household lists were not available, a brief census survey was conducted in each selected village to elicit households' main occupation and ZT adoption status to permit sample stratification. As a last step, $10 \mathrm{ZT}$ users and 15 non-users were randomly selected among all wheat growing farm households in each village. This stratified sampling approach is justified since the objective of the paper is not to assess ZT wheat adoption rates, but the performance of ZT technology at the farm household level. Given the relatively low current level of adoption, ${ }^{3}$ we had to ensure an adequate size of the adopter sub-sample through

\footnotetext{
${ }^{3}$ Based on the census data collected in the survey villages we calculated the average ZT adoption rate at $27.5 \%$; however, as these villages were randomly selected out of a population of villages with CSISA intervention, the ZT adoption rate in villages outside this population is likely to be much lower. However, we find that the infrastructural conditions of the 40 survey villages do not differ significantly from a random sample of 140 villages in the same districts in terms of access to all-weather roads, agricultural input and output markets, and agricultural extension centers; this indicates that, apart from the project intervention, the survey villages can be considered representative of villages in the six target districts in this respect.
}

stratification, which is a common and recommended procedure (cf. Deaton 1997: 13).

Data were collected from household heads ${ }^{4}$ by a team of 18 professional enumerators through structured interviews. To minimize data entry errors, electronic questionnaires with extensive skip and validation rules were used. Information was elicited about households' asset endowment and rice and wheat growing practices at farm and plot level. Furthermore, we assessed the household head's level of risk aversion using a set of self-assessment and hypothetical yield scenario questions. The comprehensive questionnaire led to an average interview time of $2.5 \mathrm{~h}$; to avoid respondent fatigue, interviews were usually completed in two sessions.

Based on soil characteristics, rainfall, temperature and terrain the agricultural ministry of Bihar has identified four major agro-ecological zones in Bihar (DoA 2014): the North Alluvial Plain (Zone I), the North-East Alluvial Plain (Zone II), the South-East Alluvial Plain (Zone III-A) and the SouthWest Alluvial Plain (Zone III-B). We use this classification for a sub-division of the research districts by agro-ecological zone, whereby we differentiate between (1) Vaishali, Samastipur and Begusarai (falling within Zone I), (2) Bhojpur and Buxar (Zone III-B), and (3) Lakhisarai (Zone III-A).

\section{Methodological approach}

\section{Model estimation strategy}

There may be systematic differences between ZT users and non-users regarding the agro-ecological conditions they operate in, as well as the type and level of input use and the management thereof. To derive an unbiased estimate of the effect that current ZT practices have on farmers' wheat yields, differences in agro-ecological conditions, input levels, and input management must be controlled for at the same time, allowing a ceteris paribus interpretation of ZT effects. We achieved this by estimating a stochastic frontier production function for wheat based on plot-level data from the 2011/12 and 2012/13 rabi seasons.

A production frontier represents the maximum output attainable for a given set of inputs and a given production technology (Farrell 1957). Failure to attain the frontier output implies the existence of technical inefficiency. However, especially in developing country agriculture, empirical data may be heavily contaminated by statistical noise due to measurement errors, variability in climatic and edaphic conditions, or affliction of crops with pests and diseases. Unlike Data

\footnotetext{
${ }^{4}$ Household heads were male in $98 \%$ of cases. Due to the non-sensitive nature of the research topic, the male enumerators did not face any problem in interviewing the few female household heads.
} 
Envelopment Analysis (DEA) that attributes any deviation from the frontier output to inefficiency (cf. Seiford 1996), stochastic frontiers accommodate statistical noise. The stochastic production frontier was independently proposed by Aigner et al. (1977) and Meeusen and van den Broeck (1977)) and is defined as follows:

$Y_{i}=F\left(X_{i} ; \beta\right) \exp \left(V_{i}-U_{i}\right) \quad, \mathrm{i}=1,2, \ldots, \mathrm{N}$,

where

$\mathrm{Y}=$ Quantity (or value) of output of the i-th firm.

$\mathrm{F}(\cdot)=$ Suitable production function.

$\mathrm{X}=$ Vector of input quantities.

$\beta=$ Vector of parameters to be estimated.

$\mathrm{V}=$ Random error term.

$\mathrm{U}=$ Non-negative error term representing technical inefficiency.

$\mathrm{V}$ is a random variable, assumed to be independently and identically distributed as $\mathrm{N}\left(0, \sigma_{\mathrm{v}}\right)$. U, which accounts for systematic departures from the frontier, i.e. technical inefficiency, is assumed to follow a particular one-sided distribution. A number of different distributions have been proposed in the literature, namely the half-normal and exponential (e.g. by Aigner et al. 1977), the truncated normal (Stevenson 1980), and the two-parameter Gamma distribution (Greene 1990). The technical efficiency (TE) measure for the i-th household $T E_{i}=\exp \left(-U_{i}\right) \in[0,1]$ is the ratio of the observed output and the maximum attainable output at the frontier. The maximum likelihood (ML) estimation of equation (1) yields estimates of $\beta$ and $\gamma$ where $\gamma=\sigma_{U}^{2} / \sigma^{2} \in[0,1]$, and $\sigma^{2}=\sigma_{U}^{2}+\sigma_{V}^{2}$. Hence, the model separates the residuals into a normally distributed random error and a one-sided error term reflecting technical inefficiency; the latter is related to input management and measures the degree to which a farmer was able to obtain the maximum possible output for a given vector of inputs. Based on observable factors, the model thus controls for potential selection bias between ZT users and non-users by accounting not only for differences in input levels, but also for differences in input management. We acknowledge that our estimation approach does not control for unobservable factors that may potentially cause selection bias. An instrumental variable approach that would correct for unobservables could not be implemented due to lacking instruments for the ZT adoption variable. However, we mitigate this limitation by including a measure of the household head's level of risk aversion as an inefficiency determinant, which typically remains an unobserved factor (see the description of variables below).

A number of empirical studies, such as Pitt and Lee (1981) and Kalirajan (1981) have investigated the determinants of technical inefficiency by regressing the efficiency estimates on firm-specific characteristics in a second-stage analysis. However, this approach is inconsistent in its distributional assumptions: in the first stage, the efficiency effects are required to be independently and identically distributed (Jondrow et al. 1982), whereas in the second stage they are assumed to be a function of firm-specific factors, which implies that they are not identically distributed. Kumbhakar et al. (1991) and Reifschneider and Stevenson (1991) noted this inconsistency and specified Stochastic Frontier models in which the inefficiency effects were defined to be explicit functions of firm-specific factors, and all parameters were estimated in a single-stage ML procedure. Battese and Coelli (1995) extended this approach to accommodate panel data. In their model, the TE effects, $U$, are obtained by truncation (at zero) of the normal distribution with mean $\mu_{\mathrm{it}}$ and variance $\sigma_{U}^{2}$, such that $\mu_{i t}=Z_{i t} \delta$, where $Z_{i t}$ is a vector of firm-specific explanatory variables, and $\delta$ is a vector of parameters to be estimated. The present study applies the Battese and Coelli (1995) model to derive unbiased estimates of the yield effects of current ZT practices in Bihar.

\section{Model specification}

The Stochastic Frontier for wheat has a Cobb-Douglas type functional form and is specified as follows:

$$
\begin{aligned}
\operatorname{In} Y_{i t}=\beta_{0} & +\sum_{k=1}^{l} \beta_{k} \ln \left(X_{k i t}\right)+\sum_{m=1}^{18} \beta_{0 m} D_{m i t}+\sum_{c=1}^{2} \sum_{z=1}^{3} \beta_{c z} Z T_{\text {czit }} \\
& +\sum_{s=1}^{2} \sum_{z=1}^{3} \beta_{s z} E S_{\text {szit }}+V_{i t}-U_{i t}
\end{aligned}
$$

where

$\ln \mathrm{Y}=$ Natural logarithm (ln) of the output.

$\mathrm{i}=$ Household index $(i=1, \ldots, 968)$.

$\mathrm{t}=$ Time index $(t=1,2)$.

$\beta=$ Vector of parameters to be estimated.

$\ln X_{k}=\ln$ of the input vector.

$\mathrm{D}_{\mathrm{m}}=$ Vector of dummy variables unrelated to ZT or ES.

$\mathrm{ZT}_{\mathrm{cz}}=$ Vector of dummy variables indicating use of zerotillage, differentiated by cropping system (c) and agroecological zone (z).

$\mathrm{ES}_{\mathrm{sz}}=$ Vector of dummy variables indicating early sowing, differentiated by season (s) and $\mathrm{z}$.

$\mathrm{V}=\mathrm{N}\left(0, \sigma_{\mathrm{v}}\right)$ distributed random error term.

$\mathrm{U}=$ Non-negative error term representing technical inefficiency.

The non-negative error component is specified as a function of potential household-specific determinants of technical inefficiency:

$U_{i t}=\delta_{0}+\sum_{r=1}^{8} \delta_{r} Z_{r i t}+W_{i t}$

where

$\delta=$ Vector of parameters to be estimated. 
$\mathrm{Z}_{\mathrm{r}}=$ Vector of potential inefficiency determinants.

$\mathrm{W}=\mathrm{N}\left(0, \sigma_{\mathrm{u}}\right)$ distributed random variable, where $\sigma_{\mathrm{u}}$ is defined such that $U_{\text {it }} \geq 0$.

The Stata 13 software package (www.stata.com) was used to obtain ML estimates of the model parameters.

Table 1 provides the definitions and summary statistics of all variables contained in the model. The logged quantity of wheat harvested is the dependent variable, and the logged quantities of land, labor, and capital inputs are explanatory variables. Due to the log-log model specification, the coefficients on the logged input variables are interpreted as partial production elasticities, indicating the percentage change in output for a onepercent increase in the respective input factor. Apart from continuous input factors relating to land, labor, and capital, the regression model contains a number of dummy variables to account for differences in agroecological zones, soil type, irrigation management, wheat variety used, and seed replacement. Their definitions are straightforward and can be gleaned from Table 1.

The inclusion of the following variables necessitates some explanation: herbicides and pesticides were only applied in $16 \%$ and $7 \%$ of observations, respectively. It may be that cases with and without such inputs differ with regard to weed and pest pressure, thus potentially affecting yield. The dummy variables Herbicides used and Pesticides used account for this potential effect and avoid biased parameter estimates on continuous variables measuring herbicide and pesticide expenses (cf. Battese 1997). Furthermore, we found that harvest and threshing practices, especially the use of a combine harvester versus manual harvesting and threshing, differed significantly between ZT users and non-users; at the same time, they potentially affect the dependent variable through varying harvest- and threshing related losses and have important implications for labor use. Therefore, we controlled for different harvest and threshing practices using dummy variables (whereby the use of a drum thresher is the base practice) and limited the labor input variable to all pre-harvesting activities.

Regarding crop establishment, the base technology is CT wheat with broadcast sowing. To estimate the effect of ZT on wheat yield, the model contains respective dummy variables. To derive a reliable estimate of the effect in the prevailing rice-wheat cropping system, we differentiated the case where ZT wheat is preceded by rice (variable $Z T W$-rice, $92.3 \%$ of $Z T$ observations) and the case where ZT wheat is preceded by any other crop (ZTW-other, $7.7 \%$ ). While the former represents a discontinuous ZT system with soil puddling $(85.6 \%$ of cases) or dry tillage $(14.4 \%)$ in the kharif rice component, the latter can include ZT also during the kharif season. We further accounted for the case where a ZT drill was used for line-sowing (LS) of wheat after soil tillage (Line-sown, $10.9 \%$ of observations). To allow the yield effects of ZT and line-sowing to vary between agro-ecological zones, we included respective interaction terms. The fact that ZT facilitates earlier sowing of wheat and, therefore, helps to avoid yield depression due to terminal heat stress has been emphasized in the literature (Erenstein and Laxmi 2008; Chauhan et al. 2012; Gathala et al. 2013; Mehla et al. 2000). Part of the yield effect of ZT has typically been attributed to an advancement of sowing times (e.g., Mehla et al. 2000). To be able to disentangle the yield effects of early sowing and ZT, dummy variables account for whether or not wheat was sown before December 01; alternatively, November 15 was tested as cut-off date for early sowing, but the data did not support any statistically significant effect on wheat yields for the years represented in our sample. Again, we included respective interaction terms with agroecological zone dummy variables. We also allowed the effect of early sowing to vary across seasons to accommodate potential variations in rainfall and temperature.

To test the robustness of our regression results, we estimated models that differed in their level of aggregation of the capital input variable and ZT and LS effects: Model 1 uses the total non-labor ${ }^{5}$ capital input and overall ZT and LS effects as explanatory variables; Model 2 uses the aggregate capital input variable, but differentiates ZT and LS effects by agro-ecological zone; finally, Model 3 differentiates physical inputs of seed and nutrients, monetary inputs for herbicides and pesticides, and the sum of remaining non-labor capital inputs (variable Partial non-labor capital input) to gain insights into the partial production elasticities of more specific input factors; it also estimates zone-specific ZT and LS effects.

All model specifications contain the same set of potential inefficiency determinants $\left(Z_{r}\right.$ in Eq. 3$)$ which are based on Bravo-Ureta and Pinheiro's (1993) review of the empirical literature on farm-specific determinants of efficiency in developing country agriculture, and our own considerations. The variable Female controls for potential gender-related TE effects; however, the sample includes only 22 observations from a total of 14 femaleheaded households. A relatively high level of education (Higher education) is expected to have a positive effect on TE since it greatly facilitates the acquisition and

\footnotetext{
${ }^{5}$ Expenses for hired labor are excluded as hired labor is captured by the labor input variable.
} 
Table 1 Definitions and summary statistics of dependent and explanatory variables in the production frontier for wheat cultivation in Bihar $(\mathrm{N}=1444)$

Variable name Definition Std. Dev.

Dependent variable ${ }^{1}$

Wheat grain output

$=$ Logged quantity of wheat grain harvested $(\mathrm{kg})$

$\mathbf{1 4 9 9 . 9 4 5 \quad 1 9 0 1 . 6 4 5}$

Explanatory variables

1. Continuous input variables ${ }^{1}$

Land

Labor

Total non-labor capital input

Partial non-labor capital input

Seed

$\mathrm{N}$

$\mathrm{P}_{2} \mathrm{O}_{5}$

$\mathrm{K}_{2} \mathrm{O}$

Herbicide exp.

Pesticide exp.

2. Dummy variables

HUW-234

PBW-154

PBW-343

UP-262

Lok-1

Sonalika-1553

Fresh seed purchased

Irrigated

Pre-sowing irrig.

$>1$ post sowing irrigations

Herbicides used

Pesticides used

Combine harv.

Axial flow thresh.

Manual threshing

Loam soil

Sandy soil

Wheat damaged

Rabi 2012/13

ZTW-rice

ZTW-other

Line-sown

AgZone1

AgZone2

AgZone3

Samastipur

Begusarai

Buxar

\section{Interaction terms}

ZTW-rice*AgZone1

ZTW-other*AgZone1

ZTW- rice *AgZone2
$=$ Logged land input (ha)

$=$ Logged hired and family labor input (pre-harvest activities only; person-hours)

$=$ Logged total non-labor capital input $\left(\mathrm{INR}^{2}\right)$

$=$ Logged total non-labor capital input excl. Expenses related to fertilizer, seed, pesticides and herbicides (INR)

$=$ Logged quantity of seeds used $(\mathrm{kg})$

$=$ Logged quantity of nitrogen $(\mathrm{N})$ used $(\mathrm{g})$

$=$ Logged quantity of phosphorous $\left(\mathrm{P}_{2} \mathrm{O}_{5}\right)$ used $(\mathrm{g})$

$=$ Logged quantity of potassium $\left(\mathrm{K}_{2} \mathrm{O}\right)$ used $(\mathrm{g})$

$=$ Logged expenses for herbicides (INR)

$=$ Logged expenses for pesticides (INR)

$=$ Dummy, $=1$ if variety is HUW-234, 0 otherwise

$=$ Dummy, $=1$ if variety is PBW-154, 0 otherwise

$=$ Dummy, $=1$ if variety is PBW-343, 0 otherwise

$=$ Dummy, $=1$ if variety is UP-262, 0 otherwise

$=$ Dummy, $=1$ if variety is Lok-1, 0 otherwise

$=$ Dummy, $=1$ if variety is Sonalika-1553, 0 otherwise

$=$ Dummy, $=1$ if fresh seed is purchased, 0 otherwise

$=$ Dummy, $=1$ if wheat crop irrigated, 0 otherwise

$=$ Dummy, $=1$ if irrigated before sowing, 0 otherwise

= Dummy, $=1$ if $>1$ post-sowing irrigations were given, 0 otherwise

$=$ Dummy, $=1$ if herbicides were used, 0 otherwise

$=$ Dummy, $=1$ if pesticides were used, 0 otherwise

$=$ Dummy, $=1$ if combine harvester was used, 0 otherwise

= Dummy, $=1$ if axial flow thresher was used after manual harvesting, 0 otherwise

$=$ Dummy, $=1$ if manual threshing was used after manual harvesting, 0 otherwise

$=$ Dummy, $=1$ if soil is loam, 0 otherwise

$=$ Dummy, $=1$ if soil is sandy, 0 otherwise

$=$ Dummy, $=1$ if yield was extraordinarily reduced by pests/diseases/terminal heat, 0 otherwise

= Dummy, $=1$ for rabi season 2012/13, 0 otherwise (2011/12)

$=$ Dummy, $=1$ if zero-tillage wheat is preceded by tilled rice, 0 otherwise

$=$ Dummy, $=1$ if zero-tillage wheat is preceded by any other crop, 0 otherwise

$=$ Dummy, $=1$ if wheat was line-sown after conventional tillage, 0 otherwise

$=$ Dummy, $=1$ if $\mathrm{HH}$ is located in Vaishali or Samastipur or Begusarai

$=$ Dummy, 1 if HH is located in Bhojpur or Buxar

$=$ Dummy, $=1$ if $\mathrm{HH}$ is located in Lakhisarai

$=$ Dummy, $=1$ if $\mathrm{HH}$ is located in Samastipur district

$=$ Dummy, $=1$ if $\mathrm{HH}$ is located in Begusarai district

= Dummy, $=1$ if $\mathrm{HH}$ is located in Buxar district

=Dummy, $=1$ if ZTW \& tilled rice system in Zone 1, 0 otherwise

=Dummy, $=1$ if ZTW \& other crop system in Zone 1, 0 otherwise

=Dummy, =1 if ZTW \& tilled rice system in Zone 2, 0 otherwise
0.613

38.008

6225

3686

68.021 75.477

$\mathbf{6 4 , 3 9 2} 75,793$

$\mathbf{3 1 , 8 6 4} 38,066$

611916,710

$113 \quad 480$

$53 \quad 379$

$\mathbf{0 . 1 2 7} 0.333$

$\mathbf{0 . 0 8 9} 0.284$

$\mathbf{0 . 3 1 0} 0.463$

$\mathbf{0 . 0 9 7} 0.296$

$\mathbf{0 . 1 4 0} 0.347$

$\mathbf{0 . 0 5 2} 0.222$

$\mathbf{0 . 8 4 3} 0.364$

$\mathbf{0 . 9 6 0} 0.196$

$\mathbf{0 . 1 2 4} 0.330$

$\mathbf{0 . 8 6 0} 0.347$

$\mathbf{0 . 1 5 8} 0.365$

$\mathbf{0 . 0 7 2} 0.259$

$\mathbf{0 . 2 3 1} 0.422$

$\mathbf{0 . 4 8 1} 0.500$

$\mathbf{0 . 0 9 3} 0.291$

$\mathbf{0 . 4 0 6} 0.491$

$\mathbf{0 . 1 0 8} 0.311$

$\mathbf{0 . 2 4 3} 0.429$

$0.666 \quad 0.472$

$\mathbf{0 . 2 7 4} 0.446$

$\mathbf{0 . 0 2 3} 0.149$

$\mathbf{0 . 1 0 9} 0.312$

$\mathbf{0 . 3 1 8} 0.466$

$\mathbf{0 . 5 9 8} 0.491$

$\mathbf{0 . 0 8 4} 0.278$

$\mathbf{0 . 1 6 1} 0.368$

$\mathbf{0 . 0 8 3} 0.276$

$\mathbf{0 . 1 0 2} 0.303$

$\mathbf{0 . 0 2 4} 0.154$

$\mathbf{0 . 0 2 2} 0.147$

$\mathbf{0 . 2 1 9} 0.414$ 
Table 1 (continued)

\begin{tabular}{|c|c|c|c|}
\hline Variable name & Definition & Mean & Std. Dev. \\
\hline ZTW-other*AgZone2 & $=$ Dummy, $=1$ if ZTW \& other crop system in Zone 2,0 otherwise & 0.001 & 0.026 \\
\hline ZTW- rice *AgZone 3 & $=$ Dummy, $=1$ if ZTW \& tilled rice system in Zone 3, 0 otherwise & $\mathbf{0 . 0 3 1}$ & 0.174 \\
\hline Line-sown*AgZone1 & $=$ Dummy,$=1$ if $\mathrm{CT}$ line-sowing in Zone 1,0 otherwise & 0.068 & 0.251 \\
\hline Line-sown*AgZone2 & $=$ Dummy, $=1$ if $\mathrm{CT}$ line-sowing in Zone 2, 0 otherwise & 0.041 & 0.198 \\
\hline Early * AgZone1 * Rabi 11/12 & $=$ Interaction effect between AgZone 1, sowing before Dec. 01 and rabi season 2011/12 & 0.106 & 0.308 \\
\hline Early * AgZone2 * Rabi 11/12 & $=$ Interaction effect between AgZone 2, sowing before Dec. 01 and rabi season 2011/12 & 0.090 & 0.286 \\
\hline Early * AgZone3 * Rabi 11/12 & $=$ Interaction effect between AgZone 3, sowing before Dec. 01 and rabi season 2011/12 & 0.017 & 0.130 \\
\hline Early * AgZone1 * Rabi 12/13 & $=$ Interaction effect between AgZone 1, sowing before Dec. 01 and rabi season 2012/13 & 0.186 & 0.389 \\
\hline Early * AgZone2 * Rabi 12/13 & $=$ Interaction effect between AgZone 2, sowing before Dec. 01 and rabi season 2012/13 & 0.215 & 0.411 \\
\hline Early * AgZone3 * Rabi 12/13 & $=$ Interaction effect between AgZone 3, sowing before Dec. 01 and rabi season 2012/13 & 0.028 & 0.166 \\
\hline \multicolumn{4}{|l|}{ 4. Inefficiency determinants } \\
\hline Female & $=$ Dummy, $=1$ if $\mathrm{HH}$ head is female, 0 otherwise & 0.015 & 0.123 \\
\hline Higher education & $=$ Dummy, $=1$ if $\mathrm{HH}$ head completed 9 th grade or above, 0 otherwise & 0.226 & 0.419 \\
\hline Risk aversion index ${ }^{3}$ & $\begin{aligned}= & \text { HH head's risk aversion index, constructed by Principal Component Analysis based } \\
& \text { on self-assessment and hypothetical yield scenario questions }\end{aligned}$ & -0.037 & 1.051 \\
\hline Cultivated area & $=$ Cultivated area (acres) & 3.679 & 3.347 \\
\hline Mobile phone & $=$ Dummy, $=1$ if $\mathrm{HH}$ owns at least one mobile phone, 0 otherwise & 0.945 & 0.227 \\
\hline Farmer's association & $=$ Dummy, $=1$ if $\mathrm{HH}$ is member in Farmer's Association, 0 otherwise & 0.021 & 0.143 \\
\hline Extension access & $=$ Access to agricultural extension on a scale from 0 ( $=$ no access $)$ to 5 ( $=$ very good access $)$ & 2.568 & 1.400 \\
\hline Wheat-specialized & $=$ Dummy, $=1$ if $\mathrm{HH}$ allocated $>50 \%$ of land to wheat during rabi season, 0 otherwise & 0.847 & 0.360 \\
\hline
\end{tabular}

Note: $\mathrm{HH}=$ Household; ZTW = Zero-tillage wheat; $\mathrm{CT}=$ Conventional tillage

${ }^{1}$ For ease of interpretation, summary statistics are provided for the unlogged variables

${ }^{2}$ Indian Rupees. 1 USD $=66.5$ INR (Sept MoA 2013)

${ }^{3}$ Higher values indicate greater risk aversion

processing of information related to agricultural production. We hypothesize farmers' level of risk aversion to affect the level of input use, but also input management; for instance, at a given level of production risk, the quality of weed and pest control and irrigation may decline with increasing risk aversion that aims at reducing losses in terms of efforts spent in vain. The Risk aversion index was constructed by Principal Component Analysis and measures risk aversion on the basis of self-assessment questions and preferences of hypothetical yield scenarios that vary in the level and variability of yields. ${ }^{6}$ We included Cultivated area as a potential efficiency determinant, for whose effect there exists conflicting evidence in the literature (Alvarez and Arias 2004). Since, ceteris paribus, farmers with very

\footnotetext{
${ }^{6}$ The index is based on six variables whose absolute factor loadings ranged from 0.55 to 0.88 . The first factor yielded an Eigenvalue of 3.53 and explained $58.8 \%$ of the variance in the data. The Kaiser-Meyer-Olkin measure of sampling adequacy amounted to 0.764 , indicating a distinct and reliable first principal component (Field 2005). Hence, households' scores on the first principal component are used as the relative risk aversion index.
}

limited land resources may have incentives to increase yields through meticulous crop and input management, we expect an inverse relationship with TE. The variable Wheat-specialized indicates whether or not at least half of the cultivable area was allocated to wheat during the rabi season. Specialization was hypothesized to have a positive effect on TE because labor resources and expertise can be focused on the cultivation of one main crop. The possession of a Mobile phone facilitates farmers' exchange of ideas and experiences with respect to their crop management practices and is therefore hypothesized to enhance TE; the same rationale applies to the inclusion of a variable indicating participation of the household head in the Farmer's association. Finally, agricultural extension services provide advice and information to farmers to improve their technical competence in farming operations. Thus, Extension access, as measured by respondents' subjective rating, is expected to have an efficiency enhancing effect. The inclusion of the household head's age as potential inefficiency determinant was tested, but led to convergence problems of the ML estimator. 


\section{Results}

\section{Comparison of household and farm characteristics between zero-tillage users and non-users across agro-ecological zones}

For our analysis to yield meaningful results, we needed to account for systematic differences in agro-ecological conditions and farming systems across the research area. As outlined above, the research area is composed of three agroecological zones, as classified by the Department of Agriculture of Bihar (DoA 2014). All analyses excluded 28 households ( $2.8 \%$ of the sample) for which the data collected were judged to be unreliable. ${ }^{7}$ Table 2 displays major farm and household characteristics, differentiated by the three agro-ecological zones Vaishali, Samastipur and Begusarai (Zone 1), Bhojpur and Buxar (Zone 2) and Lakhisarai (Zone 3). Furthermore, the table compares ZT users and non-users. Hence, two levels of mean comparisons are displayed: (1) comparisons across the overall zone-specific means (in bold), using superscript letters to indicate diverging zones, and (2) comparisons between ZT users and non-users within agro-ecological zones and across the entire sample.

Apart from the household head's level of education, all the characteristics shown differ significantly across zones, indicating the potential importance of a zone-wise differentiation of the analysis. Overall household income was higher in Zone 3 than in the other zones (Col. 1), and, at $88 \%$, a significantly larger share was derived from agriculture than in Zone 1 (66\%) and Zone 2 (60\%; Col. 2). On the average, at 5.5 acres, farms in Zone 3 were approx. $57 \%$ larger than in Zone 1 (3.5 acres) and $77 \%$ larger than in Zone 2 (3.1 acres; Column 4). Consequently, the areas allocated to wheat during rabi season and to paddy during kharif season were significantly larger in Zone 3, whereby the mean paddy area also differed significantly between Zone 1 ( 0.7 acres) and Zone 2 ( 2.8 acres; Cols. 6 and 7). At $32 \%$, the area share allocated to paddy was significantly smaller in the 'upland' Zone 1 than in the 'lowland' Zones 2 and 3 at $89 \%$ and $98 \%$, respectively (Col. 9). Consequently, income from paddy production ${ }^{8}$ accounted for only a very minor share of total household income in Zone 1 (5\%), whereas its contribution was substantial in Zone 2 (29\%) and Zone 3 (39\%; Col. 11). The area share allocated to wheat also differed between the zones, being

\footnotetext{
${ }^{7}$ As the focus of the paper is on wheat productivity, wheat yields calculated from plot-level data were used as exclusion criterion. Cases with yields exceeding $10 \mathrm{Mg} \mathrm{ha}^{-1}$ were excluded, which were probably caused by a significant underestimation of plot sizes.

${ }^{8}$ This includes paddy produced for home consumption, which is valued at the same price as was received for paddy that was sold. For households that did not sell any paddy, the average district-wise sales price was used to value their produce.
}

highest in Zone 2 at $82 \%$ and lowest in Zone 3 at $59 \%$ (Col. 8).

The comparison of ZT users and non-users across the entire sample reveals significant differences with respect to all the characteristics listed. In particular, ZT users' household income exceeded that of non-users by $138 \%$, on the average (Col. 1), whereby the share derived from agriculture was 10 percentage points higher (Col. 2). At almost 9 years of schooling, the level of formal education of ZT users exceeded that of non-users who had spent only 6.7 years at school on average (Col. 3). Consistent with the much higher household income, at 4.9 acres, the farm size of ZT users was approximately $78 \%$ larger than that of non-users, at 2.7 acres (Col. 4). Plot size is a factor that may directly influence the adoption of ZT: while the main agricultural plot averaged 1.1 acres on farms of nonusers of ZT, it was approx. $84 \%$ larger (2.0 acres) on ZT users' farms ( $\mathrm{Col} 5)$. The same finding applies to the average size of all plots cultivated, which amounted to 1.0 acres and 1.8 acres, respectively. These systematic differences between users and non-users of ZT, which are statistically highly significant also in the comparisons within Zone 1 and Zone $2,{ }^{9}$ highlight the need of controlling for potential selection bias between the two groups when estimating ZT yield impacts.

\section{Comparison of conventional-tillage and zero-tillage wheat production and profitability across agro-ecological zones}

Table 3 displays major production characteristics and profitability indicators of wheat cultivation in the research area. The data are based on the households' main CT and/or ZT wheat plot and are means across rabi seasons 2011/12 and 2012/13. Not all households grew wheat in both seasons, resulting in unbalanced panel data. Table 3 differentiates between agroecological zones and, within zones, compares conventionaltillage wheat (CTW) with zero-tillage wheat (ZTW). As in Table 2, the table displays two levels of mean comparisons: (1) comparisons across the overall zone-specific means (in bold), using superscript letters to indicate diverging zones, and (2) comparisons between CTW and ZTW within agroecological zones and across the entire sample.

Column 1 of Table 3 shows that wheat yields differed significantly among all three agro-ecological zones, with yields in Zone 1 being the highest at $2.90 \mathrm{Mg} \mathrm{ha}^{-1}$, on the average, and yields in Zone 3 being the lowest at $2.23 \mathrm{Mg} \mathrm{ha}^{-1}$. Yields in Zone 2 averaged $2.63 \mathrm{Mg} \mathrm{ha}^{-1}$. In Zone 2 farmers used a higher seed rate (Col. 2) than in the other two zones. Total capital and total labor input differed substantially between all three zones, being highest in Zone 1 and lowest in Zone 3 (Cols. 8 and 9). Farmers in Zone 3 applied only $47 \%$ of the capital and $54 \%$ of the labor that farmers in Zone 1 used. The

\footnotetext{
${ }^{9}$ The level of statistical significance is lower in Zone 3 although trends are the same; this is most likely due to the small sample size in this zone.
} 


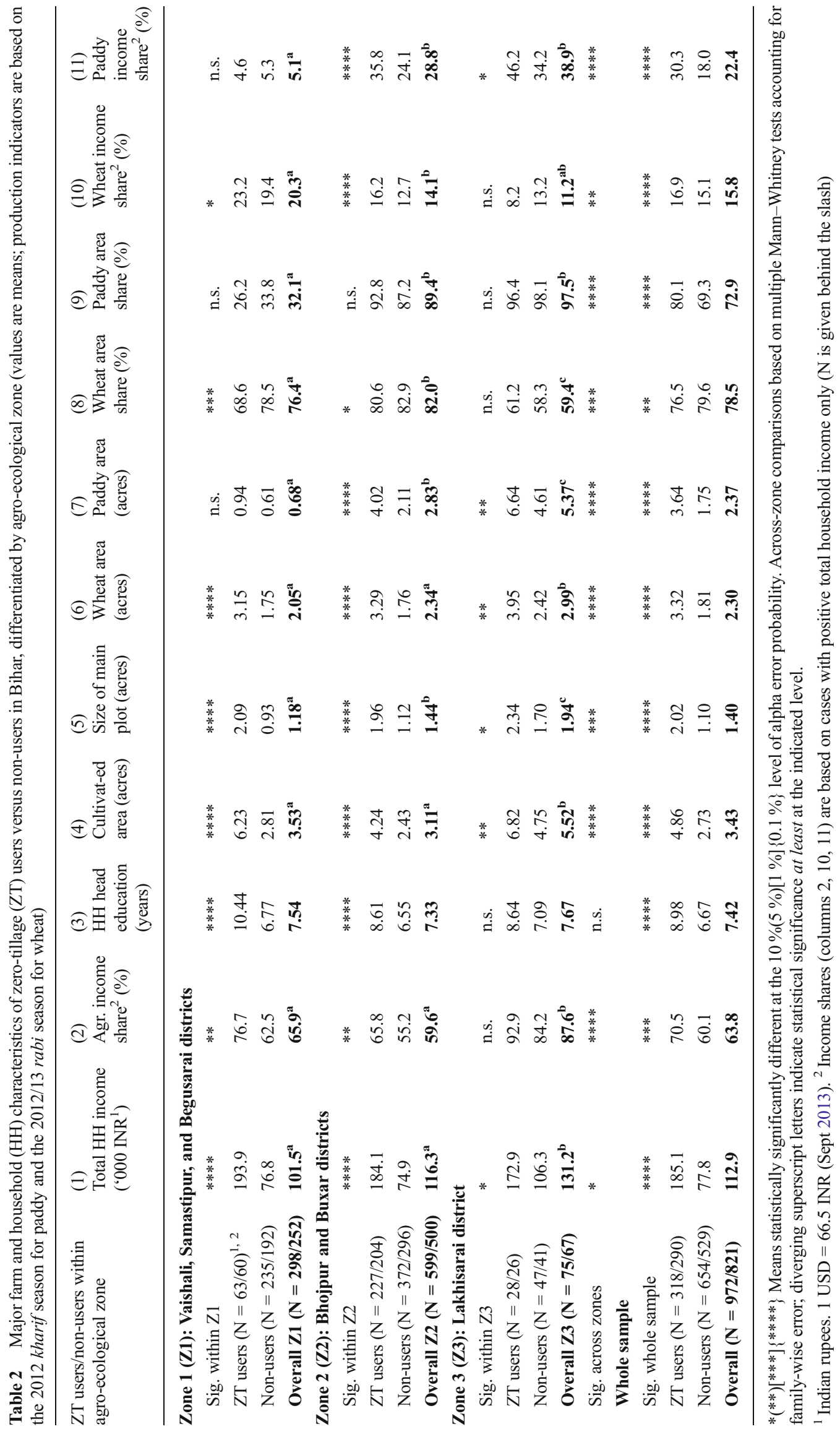




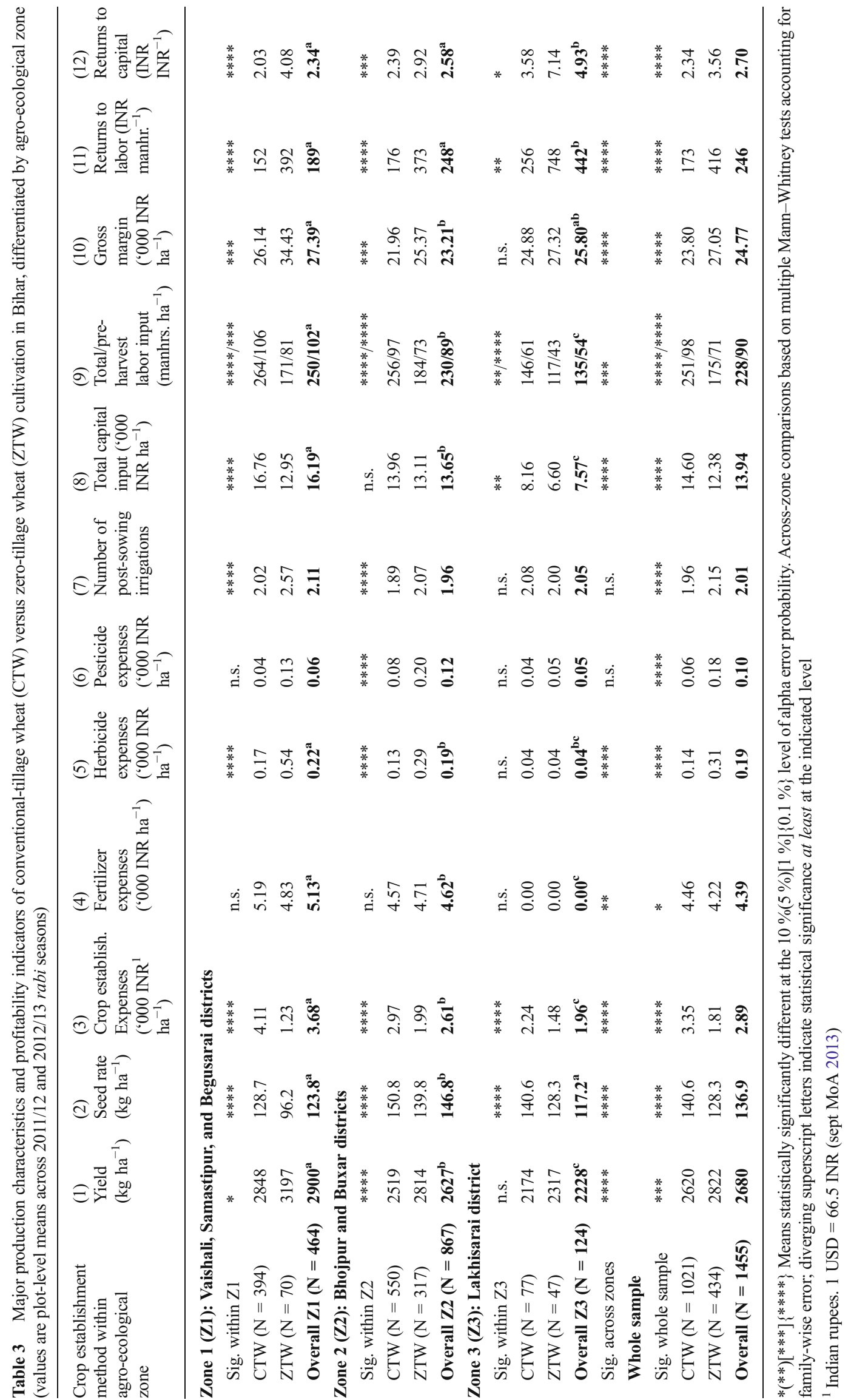


observed input intensity gradient is reflected in the average crop establishment expenses (Col. 3), fertilizer expenses (Col. 4) and, to a lesser extent, herbicide expenses (Col. 5). The difference in fertilizer expenses is particularly pronounced, showing that, while farmers spent $5130 \mathrm{INR}^{10}$ $\mathrm{ha}^{-1}$ and $4620 \mathrm{INR} \mathrm{ha}^{-1}$ in Zone 1 and Zone 2, respectively, none of the sample farmers in Zone 3 used any mineral fertilizer in wheat. As a consequence of the lower input intensity, Zone 3 farmers attained a level of gross margin from wheat production that is not statistically significantly different from that of Zone 1 farmers (Col. 10), although the yields obtained were $24 \%$ lower, on the average. At 23,800 INR ha ${ }^{-1}$, the average gross margin from wheat in Zone 2 was significantly lower than that in Zone 1, at 27,400 INR ha ${ }^{-1}$. However, when we compare the returns to labor and capital (Cols. 11 and 12), which are the most relevant economic criteria in labor and capital constrained smallholder farming systems, we find that there is no statistically significant difference between Zone 1 and Zone 2, as Zone 1 farmers achieved a higher yield and gross margin only by applying higher levels of capital and labor. Due to their much lower input intensity, Zone 3 farmers achieved substantially higher returns to labor and capital than their counterparts in the other two zones.

Turning to the comparison between CTW and ZTW, across the entire sample there exist statistically significant differences in all of the production and profitability indicators listed. On the average, ZTW plots produced a yield gain of $202 \mathrm{~kg} \mathrm{ha}^{-1}$ $(7.7 \%)$ over CTW plots (Col. 1) while using $12.3 \mathrm{~kg} \mathrm{ha}^{-1}$ $(8.8 \%)$ less seed (Col 2). ZT reduced crop establishment costs ${ }^{11}$ by $1539 \mathrm{INR} \mathrm{ha}^{-1}$ (45.9\%), on the average (Col. 3). Although herbicide and pesticide expenses were significantly higher on ZTW plots as compared to CTW plots (by $126 \%$ and $184 \%$, respectively), the absolute amounts were low, so that total capital input was $2225 \mathrm{INR} \mathrm{ha}^{-1}(15.2 \%)$ lower on ZTW than on CTW (Col. 8). This is also despite the fact that ZTW plots received a slightly higher number of post-sowing irrigations (2.15) than CTW plots (1.96; Col. 7). As a consequence of higher yields and lower input costs, ZTW plots yielded a gain in gross margin of 3250 INR ha ${ }^{-1}(13.7 \%)$ compared to CTW, on the average (Col. 10); returns to capital were increased by $1.22 \mathrm{INR}_{\mathrm{INR}}^{-1}$, representing a gain of $52.1 \%$ (Col 12). In addition to the observed differences in monetary benefits, farmers used 76 manhours ha ${ }^{-1}(30.3 \%)$ less labor on ZTW plots (Col. 9), driving up returns to labor by 243 INR manhour ${ }^{-1}(140.5 \%)$ compared to CTW plots (Col 11). However, as with all findings in this descriptive comparison, this difference must not be attributed to the use of ZT per se. Most of it is due to systematic differences in harvest and

\footnotetext{
${ }^{10}$ Indian Rupees. 1 USD $=66.5$ INR (Sept . 2013).

${ }^{11}$ These include machinery and labor costs for soil tillage and sowing or the costs associated with direct seeding using a ZT drill (in most cases a hired service); they do not include the cost of seeds.
}

threshing practices between ZT users and non-users, highlighting the need to control for selection bias between the two groups when quantifying the yield effect of ZT: at $28.6 \%$, the use of combine harvesters in the rabi season 2012/13 was approx. three times as widespread among ZT users as among non-users (9.3\%; chi-square test significant at $P<0.001$ ). Likewise, only $8.2 \%$ of ZT adopters threshed their crop manually, as compared to $16.2 \%$ of non-adopters (chi-square test significant at $P<0.01$ ). Similar differences apply to the rabi season 2011/12. If one considers preharvest activities only, the difference in labor use is reduced by $64 \%$ to 27 manhours ha ${ }^{-1}$ (Col. 9).

As indicated in Table 3, not all of the differences mentioned are statistically significant in the within-zone comparisons, especially in Zone 3. The within-zone trend, however, is consistent with the overall findings, and the lack of statistical significance is likely to be caused by the relatively small sub-sample of 77 CTW plots and 47 ZTW plots in Zone 3.

\section{Comparison of sowing times of conventional-tillage and zero-tillage wheat across agro-ecological zones}

As mentioned in the model specification section above, part of the yield effect of ZT has typically been attributed to an advancement of sowing times (e.g., Mehla et al. 2000). Figure 1 displays the distribution of sowing times in the three agro-
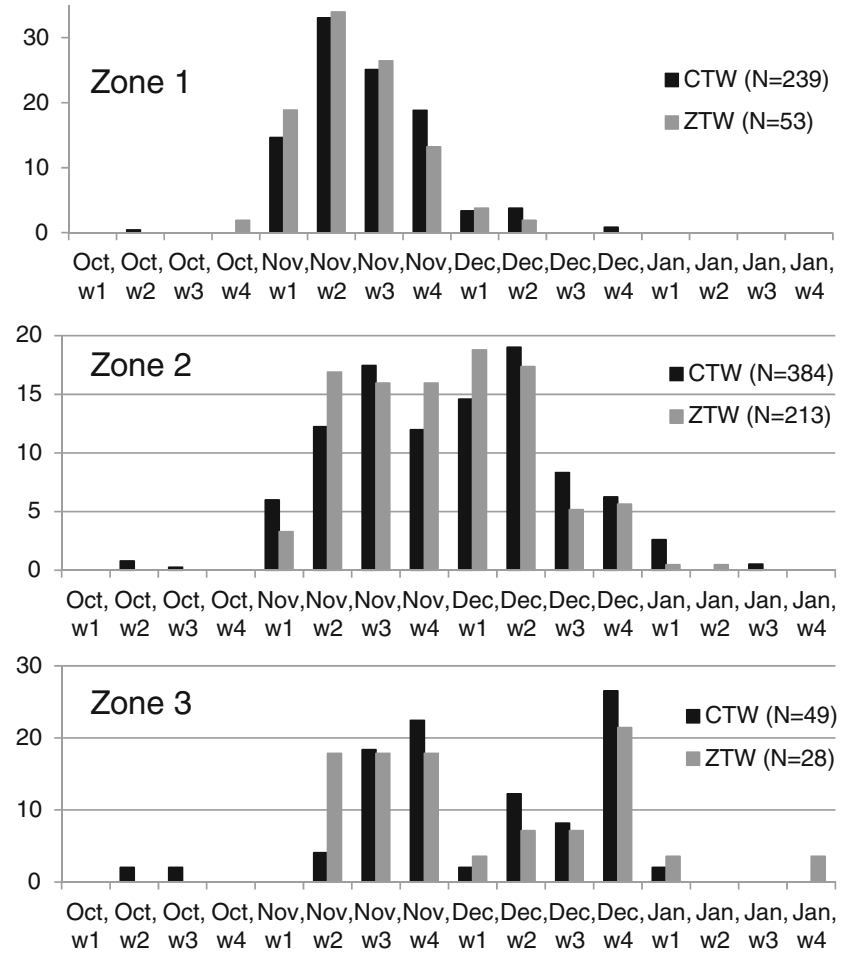

Fig. 1 Distribution of wheat sowing times in rabi season 2012/13, differentiated by conventional-tillage wheat (CTW) and zero-tillage wheat (ZTW) and agro-ecological zone (plot-level observations; weekly time scale; values on y-axes are percentages) 
ecological zones of the research area, differentiating CTW plots and ZTW plots. Recall data were collected at a weekly time resolution, leading to four weekly time slots per month (w1, .., w4) across the period October through January. The figure shows that the distribution of wheat sowing times varied across agroecological zones: in Zone 1 the distribution was relatively compact and had a single peak around the second and third week of November. In the low-lying zones 2 and 3 , the distribution was more dispersed and shifted towards December; moreover, the distributions in Zone 2 and, more clearly, in Zone 3 were characterized by two peaks, whereby extensive waterlogging was a likely major reason for the late-sowing peak. In none of the zones did we observe an obvious systematic difference in sowing times between CTW and ZTW. However, in Zone 1, the share of ZTW plots sown before November $08(28.2 \%)$ and November $15(62.4 \%)$ was significantly higher than that of CTW plots $(18.9 \%$ and $49.8 \%$, respectively; $P<0.05$ ). Also in Zone 3 we found weak statistical evidence of a larger proportion of ZTW plots being established before November 15 $(17.0 \%)$ than is the case with CTW plots $(6.4 \%$; $P<0.10)$. No significant differences were found in Zone 2. Because of the lack of a clear association of sowing time and crop establishment practice, in the following section we estimate the yield effects of ZT and early sowing independently of each other.

\section{Estimated effects of zero-tillage and early sowing on wheat yields}

As was demonstrated above, there are systematic differences between ZT users and non-users regarding farm size, education, and wealth. Therefore, the differences identified between CTW plots and ZTW plots may partly or entirely be caused by differences in the level and management of inputs between ZT users and non-users, rather than being attributable to the ZT practice per se. As elaborated in the methodology section, we estimated stochastic production frontiers for wheat to derive unbiased estimates of the yield effects of ZT and early sowing.

\section{Model specification tests}

Variance Inflation Factors (VIFs) were calculated to check for potential multicollinearity among the explanatory variables. Mean VIFs range from 2.40 in Model 2 to 2.89 in Model 3. Myers (1990) suggests that a value of 10 should not be exceeded for individual VIFs. Values around this threshold are attained only for the AgZone1 dummy variable (ranging from 11.41 in
Model 1 and 12.63 in Model 3) which is relatively highly correlated with the early-sowing dummy variable for the 2012/13 rabi season (Pearson correlation coefficient 0.70 ). However, the fact that the respective earlysowing dummy is statistically significant in both specifications demonstrates that there is no problem of inflated standard errors due to multicollinearity.

For agricultural production, constant returns to scale (CRS) are expected (cf. Heady and Dillon 1961; Battese and Broca 1997), i.e., a doubling of all input factors (including land) should entail a doubling of output. With respect to a production function this means that all partial production elasticities should sum up to one. All model specifications fulfill this condition, i.e. joint tests on the respective regression coefficients clearly fail to reject the null-hypothesis that their sum equals one.

\section{Parameter estimates in the production function}

Table 4 presents the parameter estimates of the production functions for Models 1 through 3. The models are based on plot-level data with respect to the largest CTW plot or the largest ZTW plot cultivated by a household. The data cover rabi seasons 2011/12 and 2012/13, leading to multiple observations per household. The estimation of the standard errors in the regression models accounts for clustering at the household level.

As expected, the aggregated Models 1 and 2 yield highly significant partial production elasticities for the land, labor, and capital input variables; the magnitude of the elasticities is approx. $0.63,0.11$, and 0.28 for land, labor, and capital, respectively. In the disaggregated Model 3, the elasticities on the land and labor input variables are slightly smaller since the disaggregated capital related variables explain a larger share of variance in the output variable than the aggregated capital input variable. With the exception of pesticide expenses, all continuous input variables have positive partial production elasticities, and all but the one of nitrogen input are statistically significant. An explanation for its insignificance is that almost all respondent farmers applied substantial quantities of urea, so that the observed variation of this input is located around a relatively high level where its marginal effect may be close to zero. This is not true in the case of phosphorus and potassium, whose coefficients are small but statistically highly significant. The coefficient on herbicide expenses is positive and statistically significant, whereby the dummy variable Herbicides used controls for those $84 \%$ of cases in which no herbicides were applied at all; without the latter, the coefficient on Herbicide expenses would be downward biased. No (positive) effect of pesticide expenses is supported by the data. 
Table 4 Maximum likelihood (ML) estimates of the parameters in the Stochastic Production Frontier for wheat in Bihar, accounting for zero-tillage (ZT) and early sowing (explanations in the text)

\begin{tabular}{|c|c|c|c|c|c|c|}
\hline \multirow[b]{2}{*}{ Variable } & \multicolumn{2}{|c|}{$\begin{array}{l}\text { Model 1: } \\
\text { Aggregated prod. function, } \\
\text { aggregated ZT effect }\end{array}$} & \multicolumn{2}{|c|}{$\begin{array}{l}\text { Model 2: } \\
\text { Aggregated prod. function, } \\
\text { disaggregated ZT effects }\end{array}$} & \multicolumn{2}{|c|}{$\begin{array}{l}\text { Model 3: } \\
\text { Disaggregated prod. function, } \\
\text { disaggregated ZT effects }\end{array}$} \\
\hline & Coefficient & Z-value $^{1}$ & Coefficient & Z-value $^{1}$ & Coefficient & Z-value $^{1}$ \\
\hline Land & 0.6315 & $27.56^{* * * *}$ & 0.6249 & $27.35^{* * * *}$ & 0.5617 & $22.78 * * * *$ \\
\hline Labor & 0.1058 & $5.70 * * * *$ & 0.1070 & $5.81 * * * *$ & 0.1046 & $5.74 * * * *$ \\
\hline Total non-labor capital input & 0.2798 & $11.49 * * * *$ & 0.2819 & $11.69 * * * *$ & - & \\
\hline Partial non-labor capital input & - & & - & & 0.1525 & $7.31 * * * *$ \\
\hline Seed & - & & - & & 0.1432 & $7.04 * * * *$ \\
\hline $\mathrm{N}$ & - & & - & & 0.0091 & 0.49 \\
\hline $\mathrm{P}_{2} \mathrm{O}_{5}$ & - & & - & & 0.0372 & $2.98 * * *$ \\
\hline $\mathrm{K}_{2} \mathrm{O}$ & - & & - & & 0.0125 & $3.81 * * * *$ \\
\hline Herbicide expenses & - & & - & & 0.0506 & $2.11 * *$ \\
\hline Pesticide expenses & - & & - & & -0.0120 & -0.34 \\
\hline HUW-234 ${ }^{\mathrm{d}}$ & 0.0238 & 0.50 & 0.0477 & 0.99 & 0.0527 & 1.10 \\
\hline PBW-154 ${ }^{\mathrm{d}}$ & -0.0197 & -0.38 & 0.0035 & 0.07 & -0.0045 & -0.09 \\
\hline PBW-343 ${ }^{\mathrm{d}}$ & -0.0458 & -1.10 & -0.0341 & -0.82 & -0.0414 & -1.01 \\
\hline$U P-262^{d}$ & -0.0788 & -1.59 & -0.0699 & -1.42 & -0.0499 & -1.01 \\
\hline Lok- $1^{\mathrm{d}}$ & -0.0085 & -0.18 & -0.0007 & -0.01 & 0.0161 & 0.34 \\
\hline Sonalika- $1553^{\mathrm{d}}$ & -0.1567 & -0.25 & -0.0079 & -0.13 & -0.0050 & -0.08 \\
\hline Fresh seed purchased $^{\mathrm{d}}$ & 0.1773 & $5.27 * * * *$ & 0.1859 & $5.56^{* * * *}$ & 0.1197 & $3.72 * * * *$ \\
\hline Irrigated $^{\mathrm{d}}$ & -0.2890 & $-4.01 * * * *$ & -0.2981 & $-4.16^{* * * *}$ & -0.4030 & $-5.54 * * * *$ \\
\hline Pre-sowing irrigation $^{\mathrm{d}}$ & 0.0883 & $2.41^{* *}$ & 0.0876 & $2.39^{* *}$ & 0.1197 & $3.25^{* * *}$ \\
\hline$>1$ post-sowing irrigation ${ }^{\mathrm{d}}$ & 0.0608 & 1.54 & 0.0786 & $2.00^{* *}$ & 0.0907 & $2.34 * *$ \\
\hline Herbicides used $^{\mathrm{d}}$ & -0.0329 & -0.97 & -0.0308 & -0.91 & -0.3283 & $-2.26^{* *}$ \\
\hline Pesticides used ${ }^{\mathrm{d}}$ & -0.0809 & $-1.83^{*}$ & -0.0732 & $-1.68^{*}$ & 0.0098 & 0.05 \\
\hline Combine harvester $^{\mathrm{d}}$ & 0.0894 & $2.39 * *$ & 0.0806 & $2.16^{* *}$ & 0.0841 & $2.25^{* *}$ \\
\hline Axial flow thresher ${ }^{\mathrm{d}}$ & -0.0262 & -0.82 & -0.0334 & -1.05 & -0.0274 & -0.86 \\
\hline Manual threshing $^{\mathrm{d}}$ & 0.0801 & 1.60 & 0.0642 & 1.29 & 0.0686 & 1.38 \\
\hline Loam soil $^{\mathrm{d}}$ & 0.0514 & $2.06^{* *}$ & 0.0484 & $1.95^{*}$ & 0.0257 & 1.04 \\
\hline Sandy soil ${ }^{\mathrm{d}}$ & 0.0739 & $1.74^{*}$ & 0.0725 & $1.72 *$ & 0.0666 & 1.60 \\
\hline Rabi $2012 / 13^{\mathrm{d}}$ & -0.1221 & $-3.19^{* * *}$ & -0.1155 & $-3.04 * * *$ & -0.0792 & $-2.10^{* *}$ \\
\hline Wheat damaged $^{\mathrm{d}}$ & -0.1178 & $-4.10^{* * * *}$ & -0.1301 & $-4.54 * * * *$ & -0.1419 & $-4.95 * * * *$ \\
\hline ZTW-rice ${ }^{\mathrm{d} 2}$ & 0.1605 & $5.76^{* * * *}$ & - & & - & \\
\hline ZTW-other $^{\mathrm{d}}$ & 0.3105 & $3.91 * * * *$ & - & & - & \\
\hline Line-sown ${ }^{d}$ & -0.0675 & $-1.73^{*}$ & - & & - & \\
\hline ZTW-rice*AgZone $1^{\mathrm{d}}$ & - & & 0.1806 & $2.41 * *$ & 0.1916 & $2.58 * * *$ \\
\hline ZTW-other*AgZone ${ }^{\mathrm{d}}$ & - & & 0.3395 & $4.17 * * * *$ & 0.3278 & $4.11 * * * *$ \\
\hline ZTW-rice*AgZone2 ${ }^{\mathrm{d}}$ & - & & 0.1373 & $4.39 * * * *$ & 0.1575 & $5.09 * * * *$ \\
\hline ZTW-other*AgZone2 ${ }^{\text {d }}$ & - & & 0.2358 & 0.65 & 0.4730 & 1.32 \\
\hline ZTW-rice*AgZone $3^{\text {d }}$ & - & & 0.2209 & $2.85 * * *$ & 0.2109 & $2.77 * * *$ \\
\hline Line-sown*AgZone $1^{\mathrm{d}}$ & - & & 0.0698 & 1.37 & 0.0830 & $1.65^{*}$ \\
\hline Line-sown*AgZone $2^{\mathrm{d}}$ & - & & -0.2638 & $-4.61 * * * *$ & -0.2403 & $-4.19 * * * *$ \\
\hline Early*AgZone1*Rabi 2011/12 ${ }^{\mathrm{d}}$ & 0.1539 & $1.92 *$ & 0.1498 & $1.89 *$ & 0.1476 & $1.87^{*}$ \\
\hline Early*AgZone2*Rabi 2011/12 ${ }^{\mathrm{d}}$ & -0.0452 & -0.90 & -0.0323 & -0.65 & -0.0603 & -1.22 \\
\hline Early*AgZone3*Rabi 2011/12 ${ }^{\mathrm{d}}$ & 0.2521 & $2.47 * *$ & 0.2639 & $2.61 * * *$ & 0.2490 & $2.51 * *$ \\
\hline Early*AgZone1*Rabi $2012 / 13^{\mathrm{d}}$ & 0.1772 & $2.34 * *$ & 0.1634 & $2.17 * *$ & 0.1552 & $2.07 * *$ \\
\hline Early*AgZone $2 *$ Rabi 2012/13 ${ }^{\mathrm{d}}$ & -0.0404 & -1.13 & -0.0342 & -0.96 & -0.0359 & -1.02 \\
\hline Early*AgZone3*Rabi 2012/13 ${ }^{\mathrm{d}}$ & 0.0753 & 0.85 & 0.0828 & 0.95 & 0.0783 & 0.91 \\
\hline
\end{tabular}


Table 4 (continued)

\begin{tabular}{|c|c|c|c|c|c|c|}
\hline \multirow[b]{2}{*}{ AgZone1 ${ }^{\mathrm{d}}$} & \multicolumn{2}{|c|}{$\begin{array}{l}\text { Model 1: } \\
\text { Aggregated prod. function, } \\
\text { aggregated ZT effect }\end{array}$} & \multicolumn{2}{|c|}{$\begin{array}{l}\text { Model 2: } \\
\text { Aggregated prod. function, } \\
\text { disaggregated ZT effects }\end{array}$} & \multicolumn{2}{|c|}{$\begin{array}{l}\text { Model 3: } \\
\text { Disaggregated prod. function, } \\
\quad \text { disaggregated ZT effects }\end{array}$} \\
\hline & -0.1022 & -1.28 & -0.1402 & $-1.75^{*}$ & -0.1144 & -1.40 \\
\hline AgZone $3^{d}$ & -0.0611 & -0.89 & -0.0940 & -1.25 & -0.2404 & $-3.26 * * *$ \\
\hline Samastipur ${ }^{\mathrm{d}}$ & 0.0327 & 0.58 & 0.0079 & 0.14 & -0.0491 & -0.88 \\
\hline Begusarai $^{\mathrm{d}}$ & 0.0904 & 1.48 & 0.1087 & $1.78^{*}$ & -0.0345 & -0.55 \\
\hline Buxar $^{\mathrm{d}}$ & 0.0980 & $2.31 * *$ & 0.0915 & $2.17 * *$ & -0.0175 & -0.41 \\
\hline \multirow[t]{3}{*}{ Constant } & 5.1644 & $21.94 * * * *$ & 5.1439 & $22.10 * * * *$ & 5.3534 & $23.37 * * * *$ \\
\hline & \multicolumn{2}{|l|}{$\mathrm{N}=1444$} & \multicolumn{2}{|c|}{$\mathrm{N}=1444$} & \multicolumn{2}{|c|}{$\mathrm{N}=1444$} \\
\hline & \multicolumn{2}{|c|}{ Wald Chi2 $(36)=5705.97 * * * *$} & \multicolumn{2}{|c|}{ Wald Chi2 $(40)=5892.23 * * * *$} & \multicolumn{2}{|c|}{ Wald Chi2 $(46)=6192.20 * * *$} \\
\hline
\end{tabular}

$*(* *)[* * *]\{* * *\}$ Significant at the $10 \%(5 \%)[1 \%]\{0.1 \%\}$ level of alpha error probability.

${ }^{\mathrm{d}}$ Dummy variable

${ }^{1}$ Based on robust standard errors adjusted for 968 household-level groups

${ }^{2} \mathrm{ZTW}=$ Zero-tillage wheat

With respect to the dummy explanatory variables, the results are consistent across model specifications. None of the variety-related variables are statistically significant, whereas most other explanatory variables are. The magnitude of the coefficients is very similar between Models 1 and 2, both of which use the aggregated capital input specification, and deviate somewhat in the disaggregated Model 3. Important findings are the positive effect of newly purchased seed as compared to farmer-saved seed, and the positive effects of pre-sowing irrigation and at least two postsowing irrigations. Ninety-six percent of observations are based on irrigated wheat, and the negative coefficient on the Irrigated dummy implies that the remaining $4 \%$ of rainfed wheat must be grown under extraordinarily favorable conditions. The negative signs on the variables indicating the use of herbicides and pesticides imply that these agrochemicals were applied in cases of substantial, yield-reducing weed and pest pressure. Furthermore, it is interesting to note that, compared to using a drum thresher (the base threshing method in the model), the use of a combine harvester results in an estimated yield gain of $8-9 \%$ across model specifications, which indicates a significant reduction of harvestand threshing related losses. Statistically significant soil related dummy variables in Models 1 and 2 become insignificant when seed rate and nutrient application are controlled for in Model 3.

Of particular interest are the effects of ZT and early sowing on wheat output, which are displayed in the second part of Table 4. All statistically significant coefficients are in bold, showing a robust positive yield effect of the current ZT practice, overall and differentiated by agro-ecological zone. The magnitude of the effect is similar across all models, especially as far as the prevailing ZT wheat - tilled rice system is concerned. For this system, Model 1 indicates an overall yield gain of ZT wheat as compared to CT broadcast wheat of $17.4 \%{ }^{12}(P<0.001)$, with the $95 \%$ confidence interval extending from $11.2 \%$ to $24.0 \%$. The estimates for individual agro-ecological zones range from a minimum of $14.7 \%$ for Zone 2 in Model 2 to a maximum of $24.7 \%$ for Zone 3 in Model 2. The estimated ZT-induced yield gain is even larger in the non-rice cropping system, with an overall estimate of $36.4 \%(P<0.001)$. For Zone 1 , the estimates are highly significant and consistent across Models 2 and 3 at approx. $39 \%$. For Zone 2, the respective variable controls for one single observation and is, therefore, not significantly different from zero. In Zone 3, all ZT wheat observations are based on rice - wheat cropping systems.

When we estimate the effect of ZT without differentiating rice and non-rice cropping systems, we arrive at an average yield gain of $19.0 \%(P<0.001)$. Relative to the average yield of CT wheat of $2620 \mathrm{~kg} \mathrm{ha}^{-1}$ (cf. Table 3) this results in an estimated absolute gain of $498 \mathrm{~kg} \mathrm{ha}^{-1}$, or INR 5959 when valued at the average output price received. How do these findings compare to the observed yield difference of only $202 \mathrm{~kg} \mathrm{ha}^{-1}$ in our sample? Both our regression analysis and controlled trials measure the effect of ZT ceteris paribus, i.e. keeping all other yield influencing factors constant. However, Table 3 illustrates that input use differs significantly between CTW plots and ZTW plots. Both capital and labor inputs are significantly lower on ZTW plots. In part, this can be attributed to the ZT technology (e.g., cost and labor savings in crop

\footnotetext{
${ }^{12}$ Calculated as $100 *[\exp (0.1605)-1]$, which is the correct interpretation of the marginal effect of an intercept dummy variable in a model with a logged dependent variable (see Giles 2011).
} 
Fig. 2 Schematic representation of production frontiers for zerotillage wheat (ZTW) and conventional-tillage wheat (CTW), showing the conceptual link between observed and estimated yield gains due to zerotillage

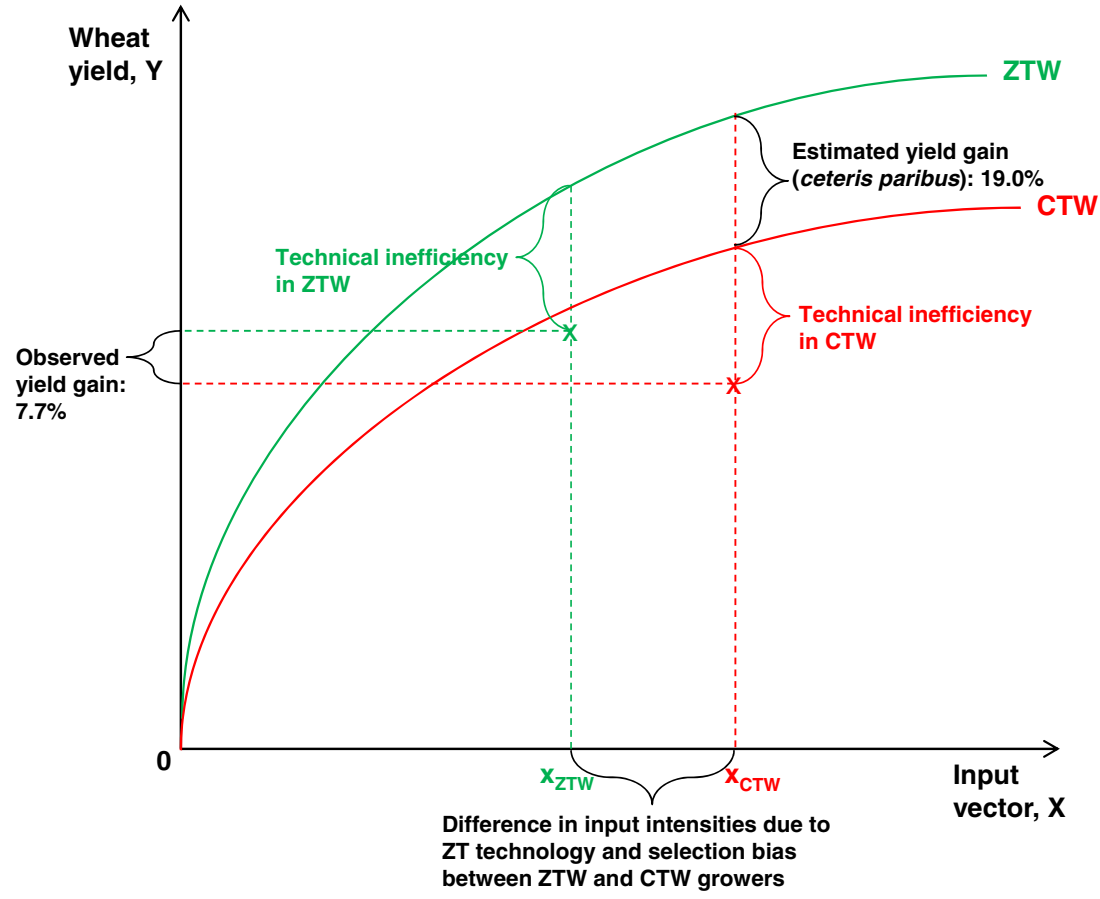

establishment), but it is also likely due to selection bias caused by systematic differences between ZT users and nonusers regarding their farm and household characteristics (cf. Table 2). Figure 2 below illustrates the conceptual relationship between estimated and observed yield gains due to ZT, using a schematic representation of production frontiers for $\mathrm{CTW}$ and ZTW. ${ }^{13}$

With respect to line-sowing of wheat after $\mathrm{CT}$, the overall yield effect is estimated to be negative in Model 1. However, the disaggregated Model 3 reveals a more differentiated picture, namely a statistically weakly significant yield gain of $8.7 \%$ in Zone 1 and a yield depression of $21.4 \%$ in Zone 2. The negative yield effect of line-sowing may be related to untimely tillage in waterlogged areas: among 59 cases of line-sowing in Zone 2, wheat was sown before November 15 in $44.1 \%$ of cases, whereas the share of CT broadcast wheat and ZT wheat sown before that date was only $16.7 \%$ (chi-square test significant at $P<0.001$ ).

The effect of early sowing of wheat is not as straightforward as that of ZT. Across model specifications, the yield gain due to sowing before December 01 is consistently estimated at $16-19 \%$ for Zone 1, both for the 2011/12 and 2012/13

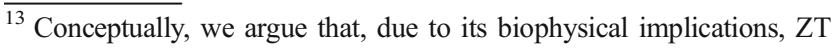
changes the agricultural production process per se, potentially leading to a shift in the production frontier, rather than affecting the technical efficiency of a given production process. Nevertheless, we also tested a model specification that includes a ZT dummy variable as an efficiency determinant, rather than as an explanatory variable in the production function. The model shows a statistically significant efficiency enhancing effect of ZT, but yields a substantially lower log likelihood value than the specification with the ZT dummy included in the production function, indicating a superior fit of the latter specification.
}

rabi season. For Zone 3, a large yield gain of approx. $28 \%$ is estimated for the 2011/12 rabi season, whereas there was no significant effect in the 2012/13 rabi season. For Zone 2, regression coefficients are consistently negative, but not significantly different from zero.

\section{Parameter estimates in the inefficiency model}

As indicated in the methodology section, the stochastic frontier model employed allows the derivation of technical efficiency (TE) estimates and the identification of efficiency determinants. Table 5 presents the TE related modeling results, which are consistent across the three specifications. The bottom part of the table shows that the estimated mean levels of TE are very similar, ranging from $74.8 \%$ to $75.8 \%$. The comparison of CTW plots and ZTW plots shows no difference in the average level of TE. Hence, on the average, wheat yields could be increased by approximately one-third both on CTW and ZTW plots if the management of the currently used inputs was optimized, i.e., without increasing the level of inputs (cf. the graphical representation in Fig. 2 above). For a correct interpretation of the efficiency determinants in Table 5 it has to be kept in mind that the dependent variable is the onesided error term reflecting technical inefficiency. Therefore, positive signs indicate TE reducing factors and negative signs TE enhancing factors. Consistently across all specifications and confirming our hypotheses elaborated in the methodology section, we find TE to increase if wheat is the main crop during the rabi season, as indicated by an area allocation of at least $50 \%$ to the crop; furthermore, there is weak evidence that better access to agricultural extension enhances TE 
Table 5 Maximum likelihood (ML) estimates of the parameters in the inefficiency models for wheat in Bihar, accounting for zero-tillage (ZT) and early sowing $(\mathrm{N}=1444$; explanations in the text)

\begin{tabular}{|c|c|c|c|c|c|c|}
\hline \multirow[b]{2}{*}{ Variable } & \multicolumn{2}{|c|}{$\begin{array}{l}\text { Model 1: } \\
\text { Aggregated prod. Function, } \\
\text { aggregated ZT effect }\end{array}$} & \multicolumn{2}{|c|}{$\begin{array}{l}\text { Model 2: } \\
\text { Aggregated prod. Function, } \\
\text { disaggregated ZT effects }\end{array}$} & \multicolumn{2}{|c|}{$\begin{array}{l}\text { Model 3: } \\
\text { Disaggregated prod. Function, } \\
\text { disaggregated ZT effects }\end{array}$} \\
\hline & Coefficient & Z-value $^{1}$ & Coefficient & Z-value ${ }^{1}$ & Coefficient & Z-value ${ }^{1}$ \\
\hline Female $^{\mathrm{d}}$ & -0.3172 & -0.89 & -0.3340 & -0.95 & -0.2992 & -0.85 \\
\hline Higher education $^{\mathrm{d}}$ & -0.0198 & -0.20 & -0.0066 & -0.07 & -0.0209 & -0.21 \\
\hline Risk aversion index & 0.1400 & $3.42 * * *$ & 0.1363 & $3.39 * * *$ & 0.1422 & $3.47 * * *$ \\
\hline Cultivated area & 0.0475 & $3.73 * * * *$ & 0.0444 & $3.55 * * * *$ & 0.0445 & $3.50 * * * *$ \\
\hline Mobile phone ${ }^{\mathrm{d}}$ & 0.1143 & 0.72 & 0.1114 & 0.71 & 0.0994 & 0.62 \\
\hline Farmer's association $^{\mathrm{d}}$ & 0.3501 & 1.34 & 0.3455 & 1.34 & 0.4226 & 1.64 \\
\hline Extension access & -0.0604 & $-1.91^{*}$ & -0.0495 & -1.60 & -0.0637 & $-2.01 * *$ \\
\hline Wheat-specialized $^{\mathrm{d}}$ & -0.3243 & $-3.08 * * *$ & -0.3269 & $-3.15^{* * *}$ & -0.2871 & $-2.72^{* * *}$ \\
\hline \multicolumn{7}{|l|}{ Mean technical efficiency } \\
\hline $\mathrm{CTW}^{2}$ plots $(\mathrm{N}=1015)$ & 0.7548 & & 0.7509 & & 0.7606 & \\
\hline ZTW $^{2}$ plots $(\mathrm{N}=429)$ & 0.7437 & & 0.7420 & & 0.7531 & \\
\hline Sig. of difference & n.s. & & n.s. & & n.s. & \\
\hline Whole sample $(N=1444)$ & 0.7526 & & 0.7483 & & 0.7584 & \\
\hline
\end{tabular}

$\left.*^{* *}\right)[* * *]\{* * *\}$ Significant at the $10 \%(5 \%)[1 \%]\{0.1 \%\}$ level of alpha error probability

${ }^{\mathrm{d}}$ Dummy variable

${ }^{1}$ Based on robust standard errors adjusted for 968 household-level groups

${ }^{2} \mathrm{CTW}=$ Conventional-tillage wheat; ZTW $=$ Zero-tillage wheat

(statistically significant in Models 1 and 3). On the other hand, there is strong evidence that TE decreases with increasing farm size and with increasing levels of risk aversion.

\section{Discussion}

Our estimated ZT induced wheat yield gain of $498 \mathrm{~kg} \mathrm{ha}^{-1}$ in farmers' fields is in line with findings from field trials: in seven on-station trials conducted in the Eastern IGP, the average ZT induced yield increase in wheat amounted to $15 \%$, or $460 \mathrm{~kg} \mathrm{ha}^{-1}$ in absolute terms (Erenstein and Laxmi 2008); at $490 \mathrm{~kg} \mathrm{ha}^{-1}$, the average yield gain reported from on-farm trials in Bihar is also very similar to our estimates of what farmers achieve with their own management (Dhiman et al. 2003). Since the yield benefits associated with $Z T$ have been established ceteris paribus with factors such as differences in time of planting and fertilizer use controlled for in the analysis, the causal mechanisms for the estimated yield gains are likely to be associated with soil related factors. Intensive tillage typically increases evaporative losses of soil water (Schwartz et al. 2010), which in turn can reduce early plant growth under deficit irrigation conditions. Further, the higher levels of soil porosity and surface roughness following tillage increase the total volume of water applied with the first irrigation (Erenstein et al. 2007), which can result in growth reductions associated with wet field conditions and processes such as denitrification and root stunting.

It is useful to consider if ZT wheat might have carry-over effects on other crops in the annual rotation. In the prevailing rice - wheat cropping system in the research area, transplanting of rice seedlings into puddled soil is the most common practice ( $85.6 \%$ of cases in this study). Since puddling for rice significantly degrades soil structure, it is unlikely that soil physical improvements induced by ZT wheat will persist following puddling operations (see Gathala et al. 2013). Also, wheat is generally harvested in late March to early April with rice establishment occurring in June through early July, with dates varying from year to year depending on monsoon onset. Hence, there is little chance that wheat planting date changes will affect rice planting dates. On the other hand, if ZT rice or non-puddled machine-transplanted rice become more prevalent, the soil quality changes achieved with ZT wheat would more likely persist and have an influence on the rice crop. Similar principals are evident in our data, with a greater ZT-induced yield gain in non-rice cropping systems where puddling is not practised (i.e. especially in Zone 1), a result that is consistent with Gathala et al. (2013) who had similar findings in the Northwestern IGP when wheat followed maize.

Apart from tillage practices in the non-wheat component of the cropping system, the extent of crop residue retention potentially affects yields, both with and without tillage (Lal 
2006; Erenstein and Laxmi 2008). With respect to residue management, we do not find significant differences between ZT users and non-users; approx. seventy percent of farmers in both groups retained some residues of the previous crop (typically rice). As residues are widely used as fodder, cases with complete residue retention are rare, but burning (11\%) or complete removal $(5 \%)$ are also not very common. As the extent of residue retention is difficult to quantify in a household survey, this factor is not considered in our analysis.

Regarding the effect of early sowing of wheat (before December 01 ) to avoid terminal heat stress, our estimates vary across agro-ecological zones and years. Not finding any positive effect of early sowing in the low-lying Zone 2 is plausible, given that this area tends to be affected by waterlogging during November, and operating tractors under wet field conditions may cause soil compaction and, consequently, countervailing yield reductions. However, the consistently positive estimates for Zone 1 indicate that farmers are achieving substantial benefits from earlier sowing in well-drained areas. In this zone, the potential of ZT to facilitate an advancement of wheat sowing times should be better harnessed than is currently the case (cf. Fig. 1), requiring the identification of potential constraints to earlier sowing in this area as a first step.

To put our ZT induced yield benefit estimate into perspective, the economic gain of INR $5959 \mathrm{ha}^{-1}$ from the yield increase of $498 \mathrm{~kg} \mathrm{ha}^{-1}$ alone translates into a $4.9 \%$ increase in the total annual household income of the average sample household. ${ }^{14}$ When considering the cost savings in crop establishment and additional expenses for herbicides that are likely attributable to the ZT technology ${ }^{15}$ (using sample means as displayed in Table 3), the economic gain increases to INR $7334 \mathrm{ha}^{-1}$ and constitutes a $6 \%$ increase in total household income. If, for illustrative purposes, one assumed full ZT wheat adoption in Bihar with its current wheat production of approximately 5 million MT (Paulsen et al. 2012), a $19 \%$ yield increase would translate into a production increase of 950,000 MT, exceeding total wheat imports into Bihar, which were 868,000 MT in 2010/11 (ibid.). These results suggest that broad-scale adoption of ZT technology could play a major role in making Bihar self-sufficient in wheat. Hereby, it

\footnotetext{
${ }^{14}$ (1) INR $5959 \mathrm{ha}^{-1} * 0.9312$ ha $(2.3$ acres average wheat area, cf. Table 2, Col. 6) = INR 5549; (2) INR 5549/INR 112,900 (average annual household income, cf. Table 2, Col. 1) $=0.049$.

${ }^{15}$ As the dependent variable in our model is physical yield, rather than profit, expenses related to hiring labor do not feed into the capital input variable. Depending on the land-to-labor ratio and opportunity costs, farmers may choose to exchange family labor for hired labor; what feeds into the model is labor input per se. Therefore, the labor input for crop establishment (with or without tillage) is accounted for by the model, but not the cost associated with hiring a respective service or accomplishing the task using own machinery. Hence, the cost savings in crop establishment have to be treated as an additional benefit. While herbicide use varies widely among farmers, we assume here a technology-inherent difference which needs to be accounted for.
}

must be emphasized that ZT adoption hinges on the availability of service providers as tractor and ZT drill ownership is economically not tenable for the large majority of farmers. With public and private sector partners, CSISA has supported the emergence of ZT service providers among tractor owners by facilitating the purchase of ZT drills and conducting technical trainings since 2009. Consequently, the number of documented ZT service providers in Bihar increased from 17 in the 2010/11 rabi season to 1624 in 2014/15, servicing a total of approximately 44,700 acres. In the near and medium-term, achieving broad-scale ZT adoption will be contingent on the success of additional development efforts to increase the number of ZT service providers - especially in districts where a critical mass of small entrepreneurs has not yet formed. Furthermore, we find that only $32 \%$ of non-users in our sample are aware of the ZT technology. Hence, increasing the number of service providers has to go hand in hand with large-scale information campaigns to raise farmers' awareness of the technology.

\section{Conclusions and recommendations}

In the context of the dominantly irrigated wheat production systems of Bihar without adoption of 'full' conservation agriculture (i.e. ZT in combination with soil cover from crop residues), we conclude that farmers reap substantial yield and monetary benefits from ZT practices, both in upland and lowland ecologies. The practicality of early sowing of wheat varies across agro-ecological zones due to temporal differences in soil drainage, which needs to be considered when targeting extension messages. Nevertheless, our findings imply that the potential of ZT to facilitate an advancement of wheat sowing can be exploited in well-drained areas. Furthermore, the efficiency analysis indicates considerable scope to increase yields through better management of current levels of inputs, e.g., by improving the timing of field operations, with the caveat that there may be binding constraints that limit the ability of farmers to achieve the same level of TE in all fields. Additional work is required to identify the root causal factors of these inefficiencies and to prioritize differentiated intervention points matched to the needs of different farm types. To increase the number of ZT beneficiaries in the densely populated Eastern IGP and, hence, contribute to enhancing wheat productivity and food security in an environmentally sustainable manner, an expansion of the network of ZT service providers is required as tractor and drill ownership is not a tenable goal for most capital-constrained small and medium-sized farms. Furthermore, efforts are needed to raise farmers' awareness of the ZT technology and to reduce the observed scale bias in its use, which is likely to be caused by the fixed costs associated with service provision in dispersed fields. Business models that include demand aggregation and service coordination may help overcome this bias by reducing 
transaction costs. Scale bias may also lessen with time as the number of service providers increases, and competition makes the providers less selective in marketing their services.

On the whole, this study provides strong evidence that ZT for wheat provides tangible and significant yield and economic benefits to adopters across a range of production ecologies and socio-economic settings in the Indian State of Bihar, while reducing environmental externalities commonly associated with extensive tillage. ZT technology could play a major role in making Bihar self-sufficient in wheat. Hence, BGREI and other development initiatives in the region should continue to provide an enabling environment for the accelerated spread of ZT as an important element of sustainable wheat intensification in Eastern India.

Acknowledgments We gratefully acknowledge the willingness of the interviewed farm households to participate in the survey. We thank USAID and the Bill \& Melinda Gates Foundation for funding this research through the Cereal Systems Initiative for South Asia (CSISA).

Conflict of interest The authors declare that they have no conflict of interest.

Open Access This article is distributed under the terms of the Creative Commons Attribution 4.0 International License (http:// creativecommons.org/licenses/by/4.0/), which permits unrestricted use, distribution, and reproduction in any medium, provided you give appropriate credit to the original author(s) and the source, provide a link to the Creative Commons license, and indicate if changes were made.

\section{References}

Aggarwal, P. K., Joshi, P. K., Ingram, J. S. I., \& Gupta, R. K. (2004). Adapting food systems of the indo-gangetic plains to global environmental change: key information needs to improve policy formulation. Environmental Science \& Policy, 7, 487-498.

Aigner, D., Lovell, C. A. K., \& Schmidt, P. (1977). Formulation and estimation of stochastic frontier production function models. Journal of Econometrics, 6, 21-37.

Alvarez, A., \& Arias, C. (2004). Technical efficiency and farm size: a conditional analysis. Agricultural Economics, 30, 241-250.

Battese, G. E. (1997). A note on the estimation of cobb-douglas production functions when some explanatory variables have zero values. Journal of Agricultural Economics, 48(2), 250-252.

Battese, G. E., \& Broca, S. S. (1997). Functional forms of stochastic frontier production functions and models for technical inefficiency effects: a comparative study for wheat farmers in Pakistan. Journal of Productivity Analysis, 8, 395-414.

Battese, G. E., \& Coelli, T. J. (1995). A model for technical inefficiency effects in a stochastic frontier production function for panel data. Empirical Economics, 20, 325-332.

Bolliger, A., Magid, J., Amado, T. J. C., Neto, F. S., Ribeiro, M. d. F. d. S., Calegari, A., et al. (2006). Taking stock of the brazilian "zero-tillrevolution": a review of landmark research and farmers' practice. Advances in Agronomy, 91, 47-110.

Bravo-Ureta, B. E., \& Pinheiro, A. E. (1993). Efficiency analysis of developing country agriculture: a review of the frontier function literature. Agricultural and Resource Economics Review, 22(1), 88-101.
Casao, R. J., de Araujo, A. G., \& Llanillo, R. F. (2012). No-till agriculture in Southern Brazil: factors that facilitated the evolution of the system and the development of the mechanization of conservation farming. (pp. 77). Rome, Italy: Food and Agriculture Organization of the United Nations (FAO) and Instituto Agronomico do Parana (IAPAR).

Chauhan, B. S., Mahajan, G., Sardana, V., Timsina, J., \& Jat, M. L. (2012). Productivity and sustainability of the rice-wheat cropping system in the indo-gangetic plains of the indian subcontinent: problems, opportunities, and strategies. Advances in Agronomy, 117, 315-369.

D’Emden, F. H., Llewellyn, R. S., \& Burton, M. P. (2008). Factors influencing adoption of conservation tillage in australian cropping regions. Australian Journal of Agricultural and Resource Economics, 52, 169-182.

Deaton, A. (1997). The analysis of household surveys: a microeconometric approach to development policy. Baltimore:The Johns Hopkins University Press.

Derpsch, R., Friedrich, T., Kassam, A., \& Li, H. (2010). Current status of adoption of no-till farming in the world and some of its main benefits. International Journal of Agricultural Biological Engineering, 3(1), 1-25.

Dhiman, S. D., Kumar, S., \& Om, H. (2003). Shallow tillage and drill technology for wheat. Indian Farming, 53, 10-13.

DoA (2008). Bihar's agricultural development: opportunities and challenges - a report of the special task force on Bihar new Delhi: department of agriculture. Government of:India.

DoA (2014). Department of Agriculture, Bihar. http://www.krishimis.in/ WebPortal/AboutUs.aspx, accessed 02/16/2015

Erenstein, O., \& Laxmi, V. (2008). Zero-tillage impacts in India's ricewheat systems: a review. Soil and Tillage Research, 100(1-2), 1-14.

Erenstein, O., Farooq, U., Malik, R. K., \& Sharif, M. (2007). Adoption and Impacts of Zero Tillage as a Resource Conserving Technology in the Irrigated Plains of South Asia. Comprehensive Assessment of Water Management in Agriculture Research Report 19. (pp. 55). Colombo, Sri Lanka: International Water Management Institute.

Erenstein, O., Farooq, U., Malik, R. K., \& Sharif, M. (2008). On-farm impacts of zero tillage wheat in south asia's rice-wheat systems. Field Crops Research, 105, 240-252.

Farrell, M. J. (1957). The measurement of productive efficiency. Journal of the Royal Statistical Society, 120, 253-290.

Field, A. (2005). Discovering statistics using SPSS for windows (Second ed., ). London:Sage Publications.

Gathala, M. K., Kumar, V., Sharma, P. C., Saharawat, Y. S., Jat, H. S., Singh, M., et al. (2013). Optimizing intensive cereal-based systems addressing current and future drivers of agricultural change in the northwestern indo-gangetic plains of India. Agriculture, Ecosystems and Environment, 177, 85-97.

Giles, D. E. (2011). Interpreting dummy variables in semi-logarithmic regression models: exact distributional results. Econometrics Working Paper EWP1101. Victoria, Canada: Department of Economics, University of Victoria.

Greene, W. H. (1990). A gamma-distributed stochastic frontier model. Journal of Econometrics, 46, 141-163.

Heady, E. O., \& Dillon, J. L. (1961). Agricultural production functions. Ames:Iowa State University Press.

Humphreys, E., Kukal, S. S., Christen, E. W., Hira, G. S., Singh, B., Yadav, S., et al. (2010). Halting the groundwater decline in northwest India - which crop technologies will be winners? Advances in Agronomy, 107, 155-217.

Jondrow, J., Lovell, C. A. K., Materov, I. S., \& Schmidt, P. (1982). On the estimation of technical inefficiency in the stochastic frontier production function model. Journal of Econometrics, 19, 233-238.

Kalirajan, K. (1981). An econometric analysis of yield variability in paddy production. Canadian Journal of Agricultural Economics, 29, 283-294.

Krishna, V. V., \& Veettil, P. C. (2014). Productivity and efficiency impacts of conservation tillage in northwest indo-gangetic plains. Agricultural Systems, 127, 126-138. 
Kumbhakar, S. C., Ghosh, S., \& McGuckin, J. T. (1991). A generalized production frontier approach for estimating determinants of inefficiency in U.S. dairy farms. Journal of Business and Economic Statistics, 9, 279-286.

Lal, R. (2006). Enhancing crop yields in the developing countries through restoration of the soil organic carbon pool in agricultural lands. Land Degradation \& Development, 17, 197-209.

Meeusen, W., \& van den Broeck, J. (1977). Efficiency estimation from cobb-douglas production functions with composed error. International Economic Review, 18(2), 435-444.

Mehla, R. S., Verma, J. K., Gupta, R. K., \& Hobbs, P. R. (2000). Stagnation in the productivity of wheat in the indo-gangetic plains: zero-till-seedCum-fertilizer drill as an integrated solution. In Rice-wheat consortium paper series 8 . New Delhi: Rice-Wheat Consortium.

MoA (2013). Agricultural statistics at a glance 2013. Department of agriculture and cooperation. Ministry of Agriculture, Government of India:New Delhi.

MoHA (2013). Sample registration system (SRS) statistical report 2012, office of the registrar general. New Delhi:Ministry of Home Affairs, Government of India.

Myers, R. (1990). Classical and modern regression with applications (Second ed., ). Boston, MA:Duxbury.

Paulsen, J., Bergh, K., Chew, A., Gugerty, M. K., \& Anderson, C. L. (2012). Wheat value chain: Bihar. Evans School Policy Analysis and Research (EPAR) Brief No. 202. Seattle: Evans School of Public Affairs, University of Washington.

Pitt, M. M., \& Lee, L. F. (1981). Measurement and sources of technical inefficiency in the indonesian weaving industry. Journal of Development Economics, 9, 43-64.

Pittelkow, C. M., Liang, X., Linquist, B. A., van Groenigen, K. J., Lee, J., Lundy, M. E., et al. (2014). Productivity limits and potentials of the principles of conservation agriculture. Nature. doi:10.1038/ nature13809.

Reifschneider, D., \& Stevenson, R. (1991). Systematic departures from the frontier: a framework for the analysis of firm inefficiency. International Economic Review, 32(3), 715-723.

Schwartz, R. C., Baumhardt, R. L., \& Evett, S. R. (2010). Tillage effects on soil water redistribution and bare soil evaporation throughout a season. Soil and Tillage Research, 110, 221-229.

Seiford, L. M. (1996). Data envelopment analysis: the evolution of the state of the art (1978-1995). Journal of Productivity Analysis, 7, 99-138.

Stevenson, R. E. (1980). Likelihood functions for generalized stochastic frontier estimation. Journal of Econometrics, 13, 57-66.

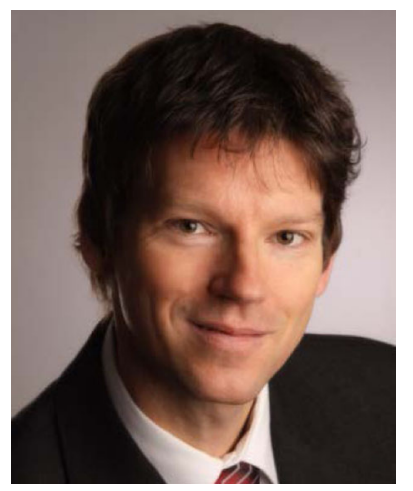

Dr. Alwin Keil is a Senior Agricultural Economist with the International Maize and Wheat Improvement Center (CIMMYT), working in the Cereal Systems Initiative for South Asia (CSISA) and being based in New Delhi, India. Before joining CIMMYT in January 2013, Alwin held a position as an assistant professor at the Department of Agricultural Economics and Social Sciences in the Tropics and Subtropics at the University of Hohenheim, Germany. From 2006 to 2012 he led a research project investigating poverty dynamics, farm households' risk management, and technology adoption in a marginal maize-based upland area of Vietnam, and prior to this he led an interdisciplinary climate impact research project in Indonesia. Alwin has extensive experience in conducting quantitative research in rural areas of developing countries (Indonesia, Philippines, Vietnam, Zambia, Ethiopia) based on representative household surveys. While his methodological focus is on ex-post econometric analyses, he also has experience in applying qualitative research methods. Alwin holds a Ph.D. in Agricultural Economics and an M.Sc. in Agricultural Sciences from Georg-August University of Goettingen, Germany. He also holds a diploma in Tropical Agriculture from University of Kassel, Germany.

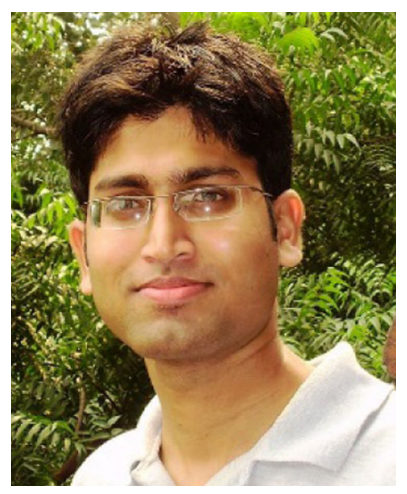

Alwin D'souza is a Research Associate with the International Maize and Wheat Improvement Centre (CIMMYT), working in the Cereal Systems Initiative for South Asia (CSISA) and being based in New Delhi, India. Alwin is also pursuing a Ph.D. in Economics from Jawaharlal Nehru University, New Delhi. He has completed his M.Phil. in economics from Jawaharlal Nehru University, New Delhi. He has research experiences from Integrated Research for Action and Development (IRADe), Centre for Civil Society (CCS), and International Food Policy Research Institute (IFPRI).

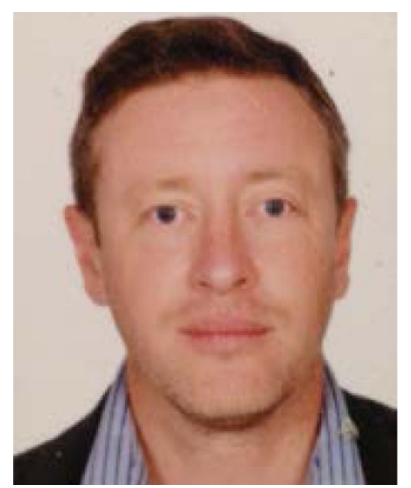

Dr. Andrew McDonald has been a systems agronomist with the International Maize and Wheat Improvement Center (CIMMYT) since January 2010. Andy has been involved with the Cereal Systems Initiative for South Asia (CSISA) since joining CIMMYT. With funding from USAID and the Bill and Melinda Gates Foundation, CSISA is a regional food security and livelihoods initiative that seeks to accelerate the rate at which farmers adopt and benefit from locally-adapted technologies through research, training, market development and new models of outreach. Andy currently serves as the project leader for CSISA across India, Bangladesh, and Nepal. He also is CIMMYT's research team leader for sustainable intensification in South Asia. Andy's specific research interests and experience involves mixed methods, including dynamic simulation, applied at the field to landscape scales. His program prioritizes process-based investigations of the influence of management and environmental factors on crop yields and yield stability. Prior to joining CIMMYT, Andy was a research scientist at Cornell University specializing in the role of climate and soil on crop growth and interactions with pests. 